\title{
Assessment of Early Markers of Cardiovascular Risk in Polycystic Ovary Syndrome
}

\author{
Krystallenia I Alexandraki, ${ }^{1,2}$ Eleni A Kandaraki, ${ }^{3,4}$ Kalliopi-Anna Poulia, ${ }^{5}$ Christina Piperi, ${ }^{6}$ Eirini Papadimitriou ${ }^{1}$ and \\ Theodoros G Papaioannou ${ }^{7}$ \\ 1.Medical School, National and Kapodistrian University of Athens, Athens, Greece; 2. Eleitho Practice, Athens, Greece; 3. Medical School, \\ European University Cyprus (EUC), Nicosia, Cyprus; 4. Department of Endocrinology \& Diabetes Mellitus, HYGEIA Hospital, Athens, Greece; \\ 5. Department of Nutrition, Laiko General Hospital, Athens, Greece; 6. Department of Biological Chemistry, School of Medicine, National and \\ Kapodistrian University of Athens, Athens, Greece; 7. First Department of Cardiology, Medical School, National and Kapodistrian University of \\ Athens, Athens, Greece.
}

DOI: https://doi.org/10.17925/EE.2021.17.1.37

$\mathrm{P}$ olycystic ovary syndrome (PCOS) is a heterogeneous syndrome, with long-term sequelae from birth to senescence. The long-term effects of PCOS are attributed to several metabolic aberrations ensuing the syndrome. In a systematic review of literature regarding the cardiovascular risk factors that accompany PCOS, we found that macrovascular function has been assessed by flow-mediated dilatation (FMD), microvascular function by venous occlusion plethysmography (VOP), and arterial structure by ultrasonographic assessment of intima-media thickness (IMT) usually of the carotid artery. Contradictory results have been reported; however, in most studies, endothelial dysfunction, an early marker of atherosclerosis assessed either by haemodynamic methods such as FMD or by biochemical methods such as endothelin-1 levels, was found to be impaired. VOP is a less-studied method, with few indices altered. IMT was found to be altered in most of the included studies, but the population was more heterogeneous. Inflammatory markers, including C-reactive protein, were also found to be altered in most studies. On the other hand, a number of interventions have been shown beneficial for the markers of cardiovascular risk, in the context of insulin-sensitizers. However, other interventions such as oral contraceptive pills or statins did not consistently show a similar beneficial effect. In summary, the early identification and eventual treatment of cardiovascular clinical and biochemical risk factors may be used in clinical practice to prevent potential 'silent' triggers of cardiovascular disease.

\section{Keywords}

Flow-mediated dilatation, intima-media thickness, nitrate-mediated dilatation, polycystic ovary syndrome, arterial stiffness, metformin, insulin resistance, insulin sensitizers, inositols, spironolactone

Disclosure: Krystallenia I Alexandraki, Eleni A Kandaraki, Kalliopi-Anna Poulia, Christina Piperi, Eirini Papadimitriou and Theodoros G Papaioannou have no financial or non-financial relationships or activities to declare in relation to this article.

Review Process: Double-blind peer review. Compliance with Ethics: This study involves a review of the literature and did not involve any studies with human or animal subjects performed by any of the authors.

Authorship: The named authors meet the Internationa Committee of Medical Journal Editors (ICMJE) criteria

for authorship of this manuscript, take responsibility for the integrity of the work as a whole, and have given final approval for the version to be published.

Access: This article is freely accessible at

touchENDOCRINOLOGY.com. (C) Touch Medical Media 2021

Received: 23 March 2020

Accepted: 22 June 2020

Published Online: 12 April 2021

Citation: touchREVIEWS in Endocrinology.

2021;17(1):37-53

Corresponding Author: Krystallenia I Alexandraki, Eleitho Practice, 132nd Kifisias Avenue, Amarousion, Attiki, Athens, Greece. E: alexandrakik@gmail.com

Support: No funding was received in

the publication of this article.
Polycystic ovary syndrome (PCOS) is a heterogeneous syndrome, considered the most common endocrinopathy in women of reproductive age, with a prevalence of $6-8 \%$ in premenopausal women. ${ }^{1.2}$ However, long-term sequelae are extended beyond the reproductive axis, being present from birth to senescence. Consequently, early detection and treatment options are in high demand to prevent long-term complications. This review aims to summarize the evidence published regarding the cardiovascular risk factors that accompany PCOS.

We systematically searched and reviewed all relevant publications in PubMed up to February 2020 using the terms 'flow-mediated dilatation and PCOS' (55 results), 'plethysmography and PCOS' (4 results), and 'intima-media thickness and PCOS' (116 results). Reviews and studies without a control group to be compared with the PCOS group were excluded. Finally, we selected 104 research studies investigating cardiovascular risk factors in PCOS compared to controls, published between 1996 and 2020, and 35 studies (14 common) investigating cardiovascular risk factors in women with PCOS before and after therapeutic interventions, published between 2005 and 2020 (Tables 1 and 2, Figure 1). . $^{3-125}$

\section{Definition of polycystic ovary syndrome}

PCOS is a heterogeneous syndrome that has remained a syndrome of unknown aetiology since its first description by Stein and Leventhal 85 years ago, and is probably one of the least understood endocrine disorders in women. ${ }^{126}$ The clinical phenotype is determined by genetic and environmental factors. ${ }^{127}$ In 2009, after a systematic review of the published literature, the Androgen Excess Society suggested that PCOS should be defined by the presence of hyperandrogenism (clinical and/or biochemical), ovarian dysfunction (oligo-anovulation and/or polycystic ovaries), and the exclusion of related disorders. Nevertheless, some endocrinologists have also addressed the possibility that there may be forms of PCOS without overt evidence of hyperandrogenism, but more data were required before validating this supposition. ${ }^{128}$ Therefore, PCOS remains a diagnosis of exclusion, and it is evident that PCOS is a polyprismatic condition. The prevalence of different phenotypes and the actual clinical significance of different laboratory and imaging variables remain under continuous investigation in an effort to identify markers of the syndrome's severity and predictors of its long-term sequelae. 
Table 1: Studies of cardiovascular risk markers (microvascular and macrovascular function, arterial structure) and inflammatory studies in polycystic ovary syndrome

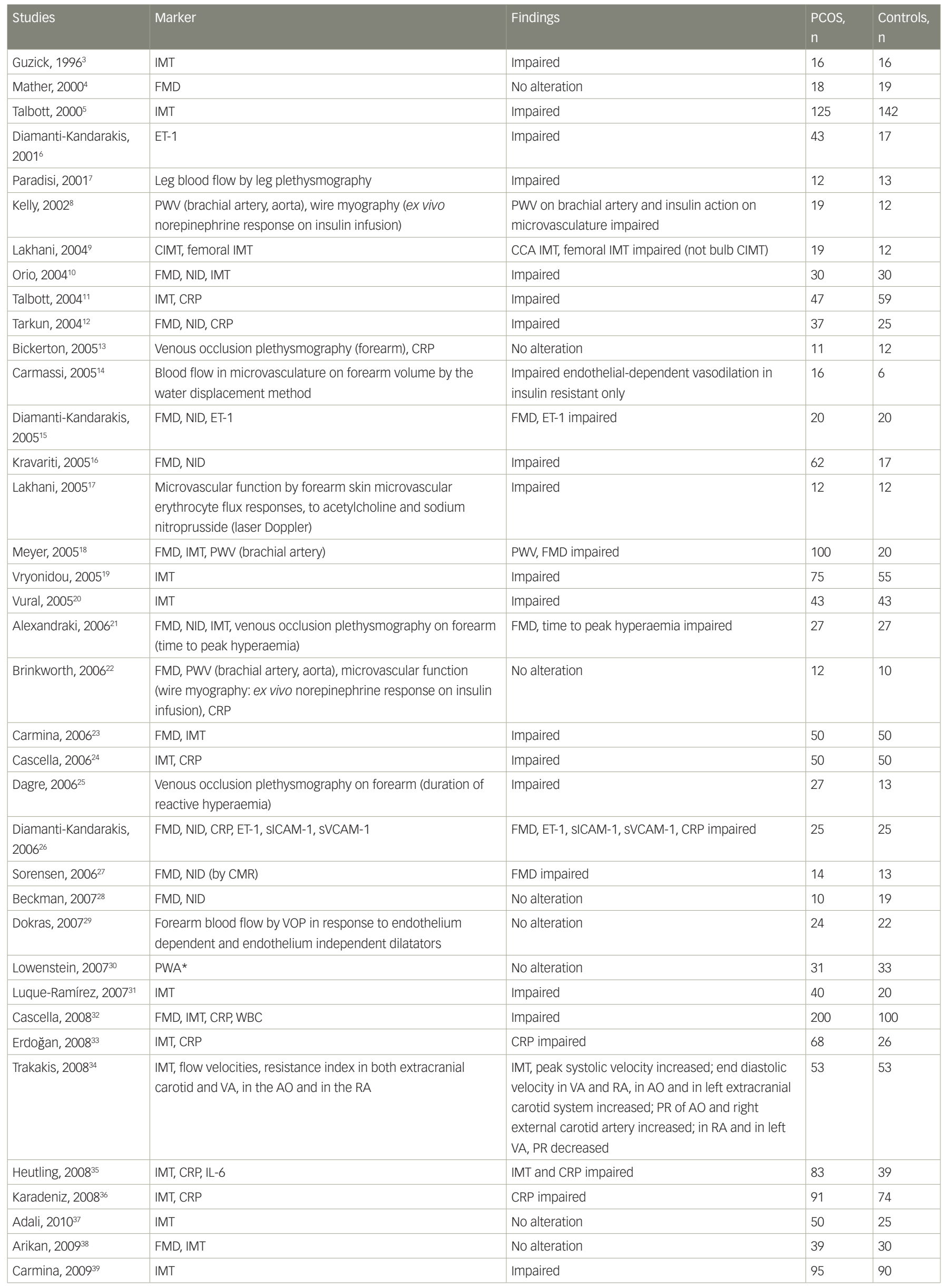


Table 1: Continued

\begin{tabular}{|c|c|c|c|c|}
\hline Studies & Marker & Findings & $\begin{array}{l}\text { PCOS, } \\
n\end{array}$ & $\begin{array}{l}\text { Controls, } \\
\mathrm{n}\end{array}$ \\
\hline Ciccone, $2009^{40}$ & IMT (carotid and common femoral arteries) & No alteration & 29 & 26 \\
\hline Cussons, $2009^{41}$ & FMD, arterial stiffness by PWV and Al & FMD impaired; arterial stiffness no impairment & 19 & 19 \\
\hline Erdogan, $2009^{42}$ & IMT, CRP & No alteration & 88 & 119 \\
\hline Kaya, $2009^{43}$ & IMT, CRP & Impaired & 46 & 46 \\
\hline Luque-Ramírez, $2009^{44}$ & FMD, NID & No alteration & 40 & 20 \\
\hline Mancini, $2009^{45}$ & FMD, ET-1 & $\begin{array}{l}\text { FMD more increased in lean controls; ET-1 increased } \\
\text { in obese PCOS versus lean controls }\end{array}$ & 24 & 20 \\
\hline Moran, $2009^{46}$ & FMD, CRP & No alteration & 80 & 27 \\
\hline Soares, $2009^{47}$ & $\begin{array}{l}\text { CCA stiffness index ( } \beta \text { ), distensibility and IMT, FMD on brachial } \\
\text { artery by US; IL-6, TNF- } \alpha, \text { CRP }\end{array}$ & $\begin{array}{l}\text { Carotid stiffness ( } \beta \text { ) index impaired (increased); } \\
\text { carotid distensibility impaired (decreased); IMT, FMD } \\
\text { not impaired }\end{array}$ & 40 & 50 \\
\hline Costa, $2008^{48}$ & IMT, CRP & IMT impaired & 57 & 37 \\
\hline Kaya, $2010^{49}$ & IMT, CRP, IL-6, IL-18 & Impaired & 60 & 60 \\
\hline Ketel, $2010^{50}$ & $\begin{array}{l}\text { Arterial stiffness obtained by US (distensibility and compliance } \\
\text { of carotid, femoral, brachial arteries); carotid elastic modulus; } \\
\text { pulse wave transit time analyzes (carotid-femoral pulse wave } \\
\text { velocity and aortic augmentation index) }\end{array}$ & No alteration & 30 & 30 \\
\hline Battaglia, $2011^{51}$ & IMT, ophthalmic artery pulsatility index & Ophthalmic artery pulsatility index impaired & 49 & 40 \\
\hline Caglar, $2011^{52}$ & IMT, CRP & Impaired & 61 & 21 \\
\hline Cakir, $2011^{53}$ & IMT & Impaired & 52 & 36 \\
\hline Coksuer, $2011^{54}$ & IMT & Impaired & 31 & 33 \\
\hline Ercan, $2011^{55}$ & IMT & Impaired & 42 & 32 \\
\hline Mohammadi, $2011^{56}$ & FMD, IMT & Impaired & 46 & 45 \\
\hline Naka, $2011^{57}$ & FMD & Impaired & 43 & 14 \\
\hline Naka, $20111^{58}$ & FMD & Impaired & 13 & 14 \\
\hline Pamuk, $2010^{59}$ & IMT, CRP & No alteration & 35 & 31 \\
\hline Pepene, $2011^{60}$ & IMT, CRP & Impaired & 64 & 20 \\
\hline Soyman, $2011^{61}$ & FMD & Impaired & 30 & 30 \\
\hline Studen, $2011^{62}$ & FMD, NID & FMD impaired & 30 & 20 \\
\hline Tan, $2011^{63}$ & IMT, CRP & Impaired & 83 & 39 \\
\hline Cakir, $2012^{64}$ & IMT & Impaired & 46 & 28 \\
\hline Cakir, $2013^{65}$ & IMT, CRP & Impaired & 50 & 39 \\
\hline Karabulut, $2012^{66}$ & $\mathrm{IMT}$ & No alteration & 46 & 43 \\
\hline Karoli, $2012^{67}$ & FMD, IMT, CRP & FMD, IMT impaired & 50 & 50 \\
\hline Pepene, $2012^{68}$ & FMD, IMT, CRP & FMD, IMT impaired & 26 & 29 \\
\hline Pepene, $2012^{69}$ & FMD, IMT, CRP & FMD impaired in lean & $\begin{array}{l}69(19 \\
\text { lean) }\end{array}$ & $\begin{array}{l}33(16 \\
\text { lean) }\end{array}$ \\
\hline Zueff, $2012^{70}$ & FMD, IMT, carotid stiffness index & No alteration & 45 & 45 \\
\hline Abali, $2013^{71}$ & IMT & Impaired & 35 & 37 \\
\hline Allameh, $2013^{72}$ & IMT & Impaired & 44 & 44 \\
\hline Barcellos, $2013^{73}$ & FMD, IMT, CAC & No alteration & 25 & 23 \\
\hline Celik, $2013^{74}$ & FMD, IMT & Impaired & 44 & 42 \\
\hline Kahal, $2013^{75}$ & $\begin{array}{l}\text { IMT, endothelial reactive hyperaemic index, CRP, sE-selectin, } \\
\text { sP-selectin, sVCAM-1, sICAM-1 }\end{array}$ & No alteration & 21 & 19 \\
\hline Kim, $2013^{76}$ & IMT & No alteration & 56 & 56 \\
\hline Tan, $2013^{77}$ & IMT, CRP, TNF- $\alpha$ & IMT, TNF- $\alpha$ impaired & 83 & 39 \\
\hline Teng, $2013^{78}$ & IMT & No alteration & 42 & 43 \\
\hline Yildir, 201379 & IMT, CRP & Impaired & 34 & 20 \\
\hline Berberoglu, $2014^{80}$ & IMT & No alteration & 42 & 20 \\
\hline Buyukkaya, $2014^{81}$ & IMT & No alteration & 25 & 25 \\
\hline
\end{tabular}


Table 1: Continued

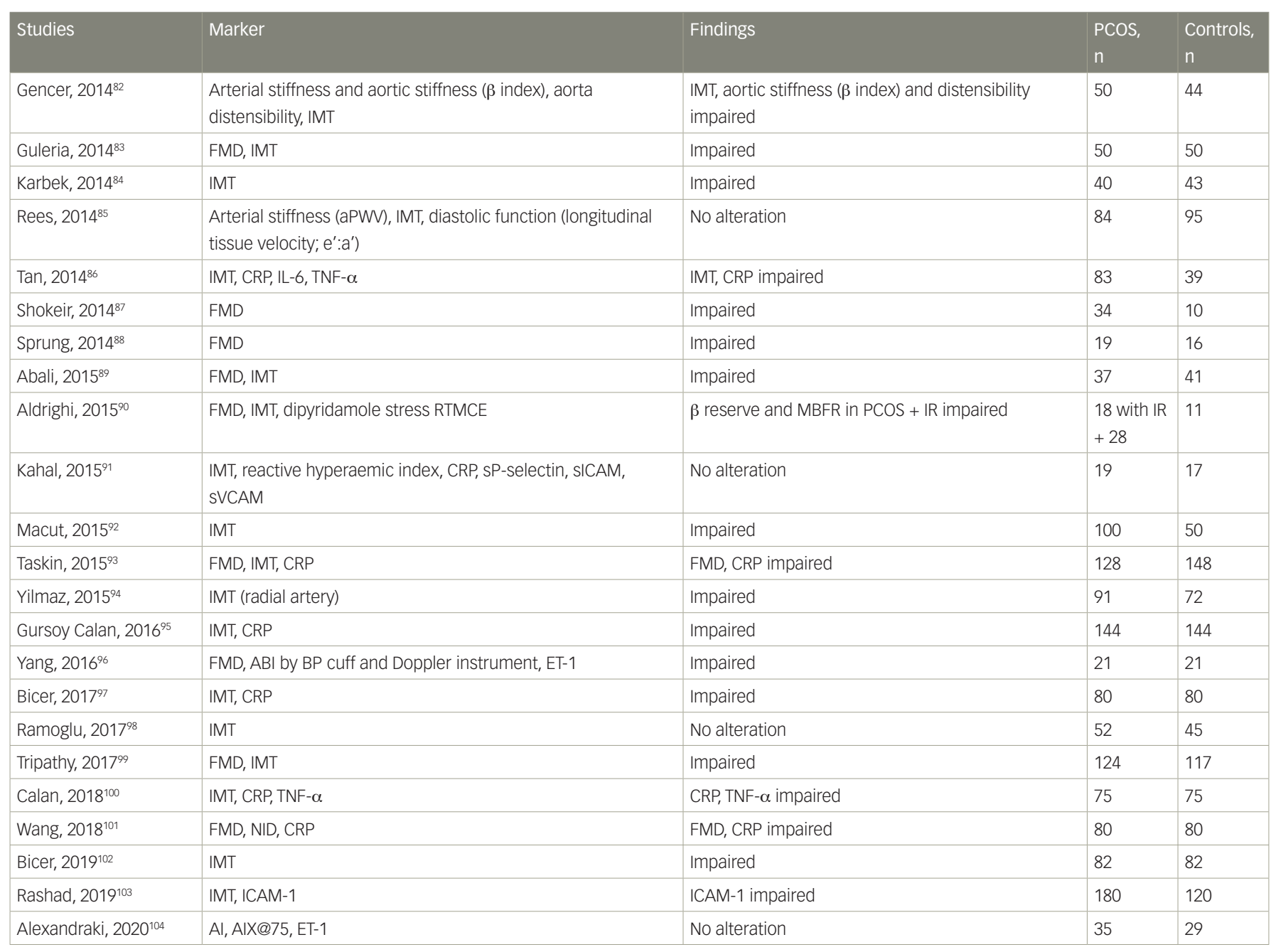

*Endothelial function determined as ratio between the arterial PWA following a 5-minute arterial occlusion in the forearm to the pre-occlusion value.

$A B I=$ ankle-brachial index; $A I=$ Augmentation Index; $A I X @ 75=A l$ corrected for heart rate; $A O=$ abdominal aorta; $a P W V=$ aortic pulse wave velocity; $B P=$ blood pressure; $C A C=$ carotid arterial compliance; $C C A=$ common carotid artery; $C I M T=$ carotid intima-media thickness; $C M R=$ cardiovascular magnetic resonance; $C R P=$ high sensitivity C-reactive protein; $E T-1=$ endothelin-1 plasma levels; FMD = flow-mediated dilatation; ICAM = intercellular adhesion molecule; $I L=$ interleukin; IMT = intima-media thickness; $I R=$ insulin resistance; MBFR = myocardial blood flow reserve; NID = nitrate-induced endothelial-independent dilatation; PCOS = polycystic ovary syndrome; $P R=$ peripheral resistance; $P W A=$ pulse-wave amplitude; $P W V=$ pulse wave velocity; $R A=$ renal arteries; $R T M C E=$ high-resolution vascular ultrasound and real time myocardial contrast echocardiography; sICAM = soluble intercellular adhesion molecule; SVCAM = soluble vascular cell adhesion molecule; sP-selectin = soluble platelet selectin; TNF = tumour necrosis factor; US = ultrasonography; VA = vertebral arteries; VOP = venous occlusion plethysmography; WBC = white blood cells.

\section{Metabolic and related features associated with polycystic ovary syndrome}

The long-term effects of PCOS are attributed to several metabolic aberrations ensuing the syndrome, including insulin resistance and hyperinsulinaemia, type 2 diabetes mellitus (T2DM), dyslipidaemia and other risk factors for cardiovascular disease (CVD). ${ }^{129-132}$

Insulin resistance is regarded as the cornerstone of the syndrome's pathophysiology and seems to have detrimental effects on several target organs, justifying the characterization of PCOS as a multisystem disorder. An overlap between PCOS and insulin resistance or metabolic syndrome has been described, since these two clinical entities share common characteristics such as abdominal obesity, elevated serum triglyceride levels, low serum high-density lipoprotein cholesterol (HDL-C) levels, abnormal blood pressure (BP) and impaired carbohydrate metabolism. ${ }^{133,134}$ The prevalence of metabolic syndrome in women with PCOS has been estimated to range from $43 \%$ to $46 \%$. ${ }^{135,136}$ More specifically, hyperinsulinaemia and insulin resistance play a critical role in the pathogenesis of PCOS and metabolic syndrome, which are both associated with a high risk for T2DM, hypertension, hyperlipidaemia and atherosclerosis. Insulin resistance is present in approximately 50-75\% of women with PCOS ${ }^{130}$ and seems to be independent from obesity. ${ }^{137-139}$ In 50\% of women with PCOS, insulin resistance appears to be related to abnormal insulin-independent serine phosphorylation of the $\beta$-subunit of insulin receptor. ${ }^{130,140}$ Reduced activity of phosphatidylinositol 3-kinase (PI3K) was also found in muscle tissue of these patients. ${ }^{141}$

With regard to the criteria used to determine insulin resistance, it is known that the hyperinsulinaemic euglycemic clamp (HEC) remains the gold standard, but due to its complexity and invasiveness it is rarely used in practice compared with other methods, which may be less precise but are non-invasive and widely acceptable in clinical research (Homeostatic Model Assessment of Insulin Resistance [HOMA-IR], Quantitative Insulin Sensitivity Check Index [QUICKI]). ${ }^{142}$ New markers have also been suggested as indirect criteria for insulin resistance, such as adipocytokines, leptin and ghrelin, but their accuracy is still under consideration. ${ }^{143}$ In general, insulin resistance, regardless of the diagnostic criteria used, is the hallmark of PCOS as demonstrated by $\mathrm{HEC}_{1}{ }^{144}$ whereas most studies are using control women to define insulin resistance. 
Table 2: Studies on medical interventions in polycystic ovary syndrome populations

\begin{tabular}{|c|c|c|c|}
\hline Studies & Drug, treatment period & $\begin{array}{l}\text { Number of patients } \\
\text { treated }\end{array}$ & Findings \\
\hline Orio, $2005^{105}$ & Metformin, 6 months & 32 & $\begin{array}{l}\text { ET-1 decreased; FMD increased; diameter after reactive hyperaemia } \\
\text { decreased; IMT decreased }\end{array}$ \\
\hline Diamanti-Kandarakis, $2005^{15}$ & Metformin, 6 months & 20 & ET-1 decreased; FMD increased; no change in NID \\
\hline Sahin, $2007^{106}$ & Metformin, 6 months & 20 & No change in IMT \\
\hline Heutling, $2008^{35}$ & Metformin, 6 months & 21 & No change in CRP/IL-6; IMT decreased \\
\hline Jensterle, $2008^{107}$ & Metformin, 6 months & 15 & FMD increased; no change in NID \\
\hline Romualdi, 2008 ${ }^{108}$ & Metformin, 6 months & 13 & FMD increased \\
\hline \multirow[t]{2}{*}{ Luque-Ramírez, $2009^{44}$} & OCP, 6 months & 15 & No change in FMD/NID \\
\hline & Metformin, 6 months & 12 & No change in FMD/NID \\
\hline \multirow[t]{2}{*}{ Luque-Ramírez, $2009^{109}$} & OCP, 6 months & 15 & IMT decreased \\
\hline & Metformin, 6 months & 19 & IMT decreased \\
\hline Mancini, 2010'111 & OCP with drospirenone, 6 months & $\begin{array}{l}28 \text { (16 lean; } \\
12 \text { overweight) }\end{array}$ & FMD increased only in overweight; no change in ET-1 \\
\hline \multirow[t]{2}{*}{ Palomba, $2010^{112}$} & Metformin, 6 months & 24 & $\begin{array}{l}\text { ET-1 decreased; FMD increased; diameter after reactive hyperaemia } \\
\text { decreased; IMT decreased }\end{array}$ \\
\hline & Metformin, folate, 6 months & 23 & $\begin{array}{l}\text { ET-1 decreased; FMD increased; diameter after reactive hyperaemia } \\
\text { decreased; IMT decreased }\end{array}$ \\
\hline Gode, $2011^{113}$ & OCP, 6 months & 40 & IMT increased; no change in FMD, NID, CRP \\
\hline \multirow[t]{2}{*}{ Naka, $2011^{57}$} & Pioglitazone, 6 months & 14 & FMD increased \\
\hline & Metformin, 6 months & 15 & FMD increased \\
\hline Naka, $2011^{58}$ & OCP, 6 months & 13 & FMD increased \\
\hline Raja-Khan, $2011^{114}$ & Atorvastatin, 6 weeks & 9 & CRP decreased; no change in FMD \\
\hline Bajuk Studen, $2013^{115}$ & $\begin{array}{l}\text { spironolactone per } 21 \text {-day for a cycle of } \\
28 \text { days, } 6 \text { months }\end{array}$ & 30 & FMD increased \\
\hline Tan, $2011^{63}$ & Metformin, 6 months & 21 & IMT decreased; no change in CRP \\
\hline Karabulut, $2012^{117}$ & OCP, 6 months & 30 & No change in IMT \\
\hline Pepene, $2012^{68}$ & Ethinylestradiol/drospirenone, 6 months & 25 & FMD increased IMT increased; no change in CRP \\
\hline \multirow[t]{2}{*}{ Vieira, $2012^{118}$} & OCP, 6 months, 12 months & 21 & $\begin{array}{l}\text { No change in FMD, IMT; carotid artery stiffness index improved at } \\
6 \text { and } 12 \text { months }\end{array}$ \\
\hline & OCP spironolactone, 6 months, 12 months & 20 & $\begin{array}{l}\text { No change in FMD, carotid artery stiffness index; IMT increased at } \\
12 \text { months }\end{array}$ \\
\hline \multirow[t]{2}{*}{ Mohiyiddeen, $2013^{119}$} & Metformin, 3 months & 17 & No change in ED and EID microcirculation \\
\hline & Rosiglitazone, 3 months & 18 & No change in ED microcirculation; EID increased \\
\hline Sprung, $2013^{120}$ & 16-week exercise programme & 10 & FMD increased \\
\hline Tan, $2013^{77}$ & Metformin, 6 months & 21 & No change in CRP, TNF- $\alpha$; IMT decreased \\
\hline Shokeir, $2014^{87}$ & Laparoscopic ovarian drilling & 34 & FMD increased \\
\hline Tan, $2014^{86}$ & Metformin, 6 months & 21 & No change in CRP, TNF- $\alpha$, IL-6; IMT decreased \\
\hline \multirow[t]{2}{*}{ Kaya, $2015^{121}$} & Metformin, OCP, 6 months & 25 & No change in FMD, IMT \\
\hline & OCP, 6 months & 25 & No change in FMD, IMT \\
\hline Kahal, $2015^{91}$ & Liraglutide, 6 months & 19 & $\begin{array}{l}\text { No change in CRP, SP-selectin, SICAM, SVCAM, reactive hyperaemic } \\
\text { index, IMT }\end{array}$ \\
\hline \multirow[t]{2}{*}{ Orio, $2016^{122}$} & $\mathrm{OCP}, 6$ months & 47 & No change in FMD, IMT, CRP \\
\hline & $\begin{array}{l}\text { Structured exercise training programme, } \\
6 \text { months }\end{array}$ & 39 & FMD increased; IMT decreased; CRP decreased \\
\hline Yang, $2016^{96}$ & Simvastatin, 6 months & 21 & ET-1 decreased; FMD increased; ABI impaired \\
\hline Wang, $2018^{101}$ & Metformin, 3 months & 80 & FMD increased; CRP decreased \\
\hline Ely, $2019^{123}$ & Heat therapy, 8-10 weeks & 9 & $\begin{array}{l}\text { CRP decreased; FMD increased; carotid wall thickness decreased; } \\
\text { femoral wall thickness decreased }\end{array}$ \\
\hline \multirow[t]{2}{*}{ Talari, $2018^{124,125}$} & Carnitine, 12 weeks & 30 & IMT decreased; no change in CRP \\
\hline & $\begin{array}{l}1,000 \text { mg omega- } 3,400 \text { IU vitamin } E \\
12 \text { weeks }\end{array}$ & 30 & IMT decreased; CRP decreased \\
\hline Alexandraki, $2020^{104}$ & Metformin, 6 months & 20 & AIX@75 decreased; ET-1 decreased \\
\hline
\end{tabular}

*Endothelial function determined as ratio between the arterial pulse-wave amplitude following a 5-minute arterial occlusion in the forearm to the pre-occlusion value. $A B I=$ ankle-brachial index; $A I X @ 75=$ Al corrected for heart rate; $C R P=$ high sensitivity $C$-reactive protein; ED = endothelium-dependent; EID = endothelium-independent; ET-1 = endothelin-1 plasma levels; FMD = flow-mediated dilatation; IL = interleukin; IMT = intima-media thickness; NID = nitrate-induced endothelial-independent dilatation; $O C P=$ oral contraceptive pill; sICAM = soluble intercellular adhesion molecule; sP-selectin = soluble platelet selectin; sVCAM = soluble vascular cell adhesion molecule; TNF = tumour necrosis factor. 
Figure 1: Search strategy

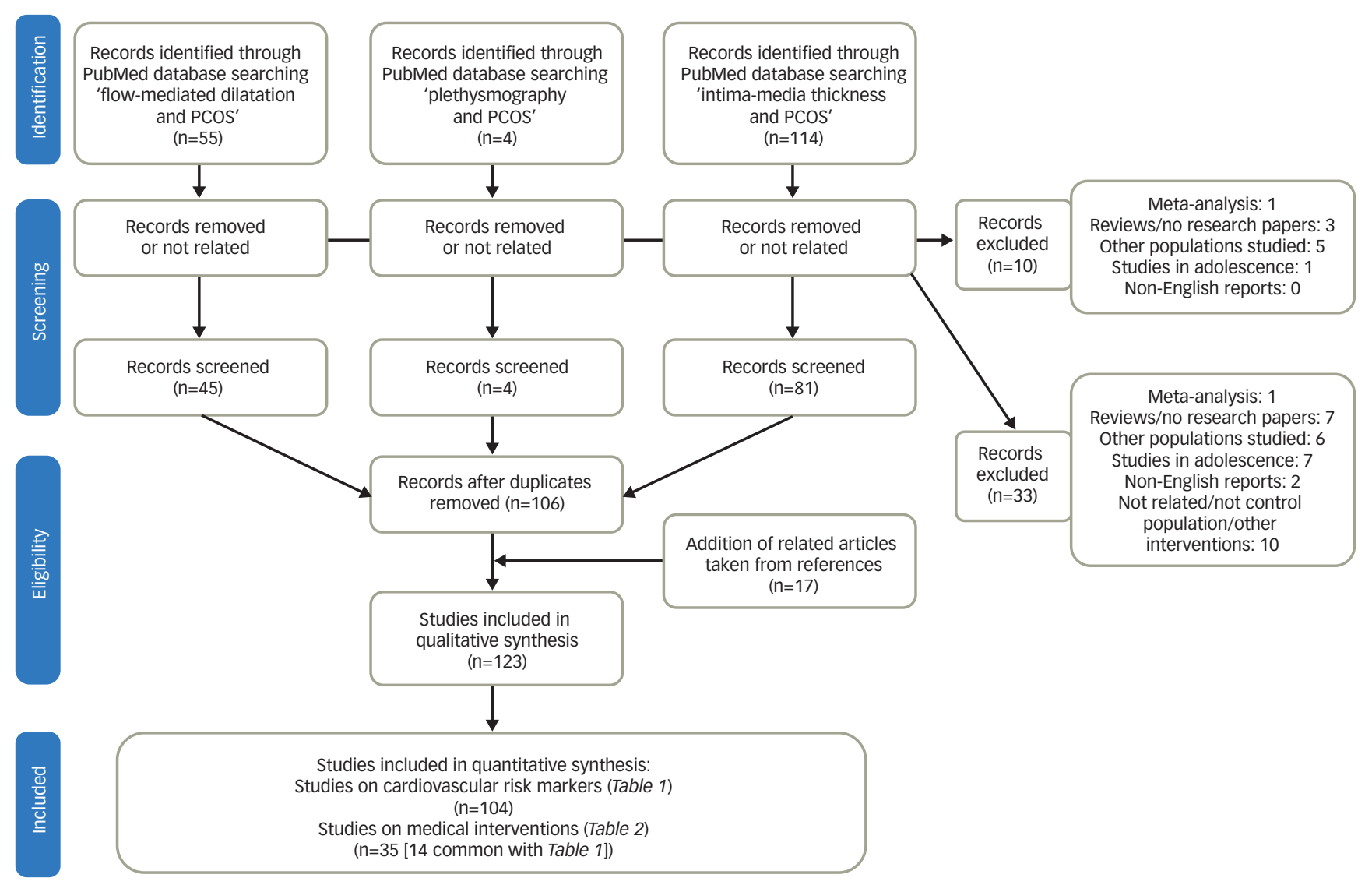

Search strategy used for the analysis of 104 studies on cardiovascular risk markers of women with polycystic ovary syndrome and 35 studies on medical interventions used to modify the cardiovascular risk factors of women with polycystic ovary syndrome.

PCOS = polycystic ovary syndrome.

Overweight and obesity, defined as a body mass index (BMI) within the range of $25.00-39.99 \mathrm{~kg} / \mathrm{m}^{2}$ (mild 25.00-29.99, and severe $>30.00-39.99 \mathrm{~kg} / \mathrm{m}^{2}$ ), have been shown to be more prevalent in women with PCOS and are further associated with hyperinsulinaemia and insulin resistance. ${ }^{45}$ The prevalence of obesity in patients with PCOS differs depending on ethnicity, being less prevalent in Europe ${ }^{146}$ and more common in the USA. ${ }^{147}$ However, both lean and obese women with PCOS display central fat distribution. ${ }^{148-150}$ Additionally, obese premenopausal women with PCOS have a 31-35\% incidence of impaired glucose tolerance, whereas $7.5-10.0 \%$ develop overt diabetes. ${ }^{151,152}$ Moreover, other clinical entities, such as non-alcoholic steatohepatitis and non-alcoholic fatty liver disease, ${ }^{153}$ as well as obstructive sleep apnoea and excessive daytime sleepiness, have been associated with insulin resistance and PCOS (Figure 2). ${ }^{154}$

\section{Parameters of cardiovascular disease}

PCOS has been reported to bear an increased risk for atherosclerosis with a calculated increased risk (relative risk) of 7.4 for myocardial infarction. ${ }^{155}$ An early sign of the atherogenic process, which results in overt CVD, is endothelial dysfunction, ${ }^{156}$ which has been comprehensively studied in PCOS. Since PCOS has been suggested to represent a female subtype of metabolic syndrome, ${ }^{134}$ carrying a potential pre-atherogenic load, patients with PCOS have increased cardiovascular risk compared with age-matched controls. ${ }^{157}$ Myocardial infarction was recorded to be seven times more likely in patients with histopathological evidence of $\mathrm{PCO},{ }^{155}$ and cardiac catheterization studies have shown more extensive coronary artery disease in these patients than in women with normal ovaries. ${ }^{158}$ Furthermore, significant subclinical carotid atherosclerosis has been demonstrated on carotid artery ultrasound in women with PCOS. ${ }^{3,5}$

This increased cardiovascular risk is likely to partly be a result of the metabolic disturbances associated with PCOS. Dyslipidaemia, diabetes (from impaired glucose tolerance to overt T2DM), and obesity are potentially cardiovascular risk factors that tend to cluster in women with PCOS. ${ }^{148,159}$ Many previous studies have documented abnormalities of insulin metabolism in both lean and overweight women with PCOS. ${ }^{130,138,160,161}$ Dyslipidaemia, insulin resistance and abdominal obesity are variable clinical features of PCOS which, irrespective of the presence of PCOS, contribute to the presence of metabolic syndrome with characteristic linkage to atheroma development and to overt risk for CVD. ${ }^{162}$ In addition, hypertension represents an uncommon and inconsistent finding in young women with PCOS, but its prevalence increases to $40 \%$ in the perimenopausal period. ${ }^{163-166}$ However, the epidemiological evidence of CVD events in relation to PCOS has not been confirmed. ${ }^{167}$

An alternative explanation for the increased cardiovascular risk in PCOS is hyperandrogenism. Possible underlying pathophysiological mechanisms include a correlation between free testosterone and systolic $\mathrm{BP}^{168}$ and a link between increased androgens and abnormal lipid metabolism. ${ }^{169,170}$ Nonetheless, the association between hyperandrogenism and cardiovascular risk is not universally accepted. ${ }^{170}$ Previous studies of obese women with PCOS have shown that hyperinsulinaemia 
Figure 2: Cardiovascular risk factors and metabolic factors in polycystic ovary syndrome

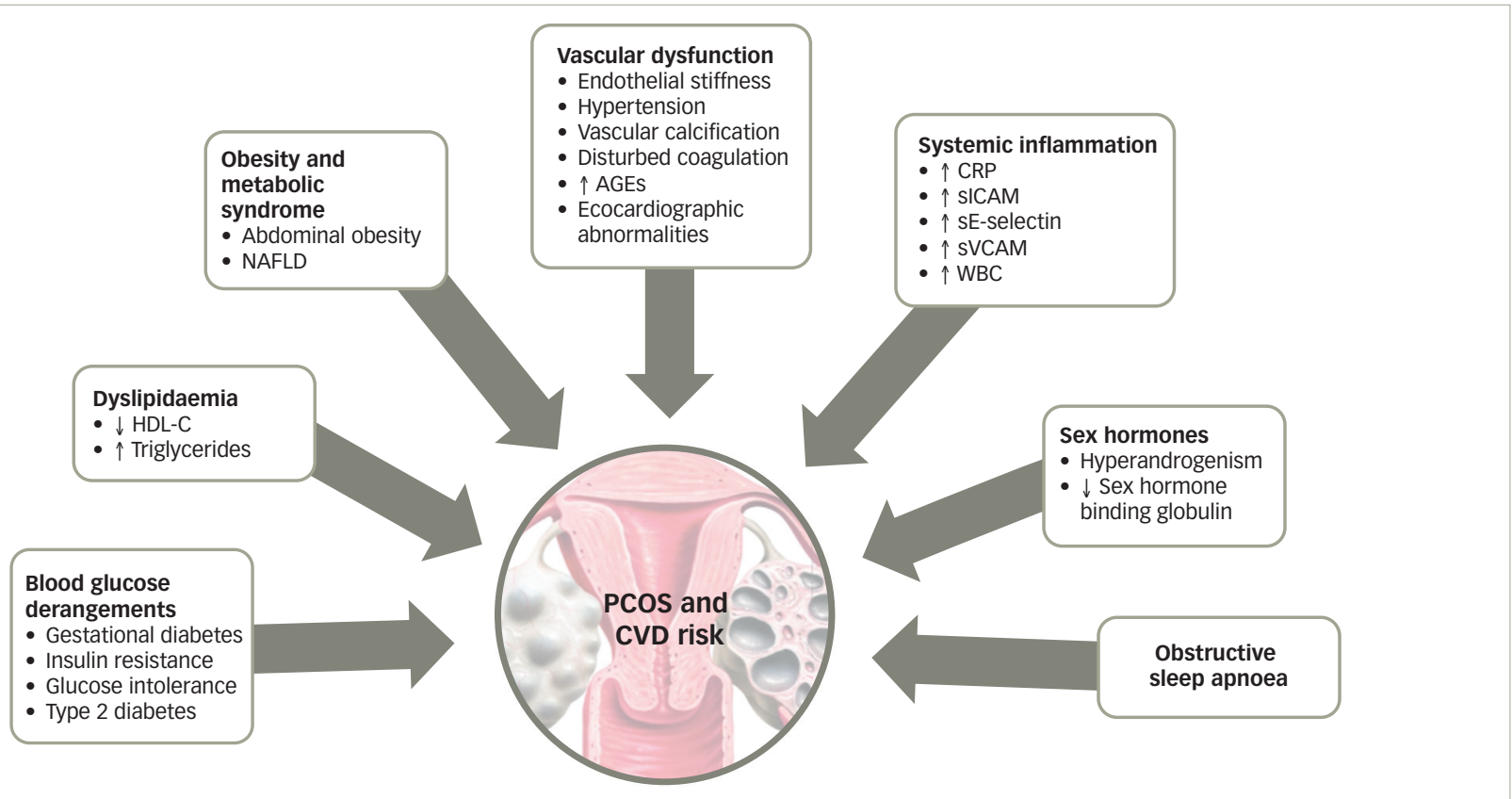

$\downarrow$ decreased/reduced; $\uparrow$ increased.

AGES = advanced glycated end-products; $C R P=C$-reactive protein; $C V D=$ cardiovascular disease; HDL-C = high-density lipoprotein cholesterol; NAFLD = non-alcoholic fatty liver disease: $P C O S=$ polycystic ovary syndrome; sE-selectin = soluble E-selectin; sICAM = soluble intercellular adhesion molecule; sVCAM = soluble vascular cell adhesion protein; $W B C=$ white blood cells.

directly reduces sex hormone binding globulin (SHBG). ${ }^{171}$ This has led to the hypothesis that SHBG might be a surrogate marker of insulin resistance in this population. ${ }^{172}$ Other studies, however, in both PCOS and non-PCOS populations suggest that BMI and percentage body fat, rather than insulin, are independent predictors of SHBG. ${ }^{173,174}$

\section{Endothelial function and polycystic ovary syndrome}

The endothelium is the target organ for a variety of metabolic risk factors. It has been demonstrated that insulin exerts a direct hypertrophic effect on the vascular endothelium and on the smooth muscle cells. ${ }^{175}$ Abnormal vascular function has been shown in PCOS, and the syndrome has been associated with surrogate cardiovascular markers, such as increased serum levels of plasminogen-activator inhibitor 1 (PAl-1), ${ }^{176}$ elevated serum levels of C-reactive protein (CRP), ${ }^{177}$ elevated advanced glycation end-products (AGES) serum levels ${ }^{178}$ and echocardiographic abnormalities. ${ }^{179-181}$ The pathophysiology remains unclear but a number of mechanisms could be implicated to link endothelial dysfunction with insulin resistance, including disturbances of subcellular signalling pathways to insulin action or other potential unifying links. ${ }^{182-184}$

\section{Haemodynamic methods for endothelial function assessment in polycystic ovary syndrome}

The endothelium plays a crucial role in regulating arterial function. Endothelial dysfunction is one of the best-understood preliminary steps in the development of atheromatous disease. ${ }^{185}$ It has been considered not only as a marker of early, possibly reversible, arterial abnormality, but also as a prognostic marker for future cardiovascular morbidity. ${ }^{186}$ Endothelial dysfunction can be studied by haemodynamic methods, like brachial flow-mediated dilatation (FMD) and venous obstructive plethysmography (VOP) on peripheral arteries, which both examine different sections of arterial bed (macro- and microcirculation, respectively) and should be considered complementary, providing different information. ${ }^{21}$
The association between insulin resistance and endothelial dysfunction has been demonstrated consistently in subjects with T2DM, obesity and metabolic syndrome. ${ }^{187}$ Thus, at a mechanistic level, endothelial dysfunction appears to occur early in the insulin-resistant state; the progression of insulin resistance to diabetes in parallel to the progression of endothelial dysfunction to atherosclerosis. ${ }^{187}$ There are several mechanisms through which insulin resistance can adversely affect the endothelium. Insulin-resistant states, such as T2DM, are characterized by increased production of free fatty acids and proinflammatory cytokines, such as tumour necrosis factor $\alpha$ (TNF- $\alpha$ ) and leptin, which contribute to endothelial dysfunction. ${ }^{188}$ There is also evidence to suggest that insulin resistance induces increased oxidant stress, which may have an important pathogenic role. ${ }^{175}$

\section{Endothelial dysfunction and flow-mediated dilatation in polycystic ovary syndrome}

Endothelial function can be estimated in conduit arteries (macrovascular function), non-invasively by high-resolution ultrasonography on the brachial artery, assessing FMD, ${ }^{189}$ an endothelial-dependent dilatation, which has been found to be correlated with coronary endothelial function, ${ }^{190}$ consequently representing an independent predictor of cardiovascular events. ${ }^{191}$ In the first published study to investigate endothelial function by FMD in patients with PCOS, no difference was shown compared to control women. ${ }^{4}$ However, few studies have confirmed these negative findings (Table 1). ${ }^{3-104}$

On the contrary, most studies undertaken in young women with PCOS, of normal weight or overweight and obese, confirm overt endothelial dysfunction. First, in young, lean women with PCOS, a 20\% drop of FMD response has been shown, compared with normal women of a similar age and BMI. ${ }^{10}$ Furthermore, the combination of FMD and the biochemical assessment by endothelin 1 (ET-1) plasma levels to assess endothelial dysfunction in young, overweight insulin resistant women with PCOS and controls, with similar age and BMI, documented 
impairment in women with PCOS, after exclusion of smooth muscle cells injury detected by nitrate-induced endothelial-independent dilatation (NID)..$^{15}$ Other parallel studies confirmed FMD impairment along with NID impairment, implying a global vascular deficit. ${ }^{12,16}$ In all these studies, insulin resistance had an impact on FMD, 12,15,16 whilst a tendency of FMD to deteriorate from lean to overweight and to obese women with PCOS was observed, even without reaching statistically significant differences. ${ }^{16}$ Notably, in lean women with PCOS, FMD was found to be negatively influenced only by hyperandrogenaemia, and in overweight women by insulin resistance and hyperandrogenaemia. ${ }^{16}$ In an effort to correct for other cardiovascular risk factors, FMD and NID were assessed in a normoglycaemic, eulipidaemic, normal BP and normal glucose tolerance PCOS group, and a control group with comparable age, BMI and waist:hip ratio. FMD, but not NID, was impaired in women with PCOS who remained insulin-resistant. ${ }^{21}$ Finally, in young overweight women with PCOS, FMD was impaired compared with ovulatory controls matched for age and BMl, and this alteration was correlated to insulin resistance but not to the adipokines measured. ${ }^{23}$ Endothelial function has also been assessed by the use of novel technologies using cardiovascular magnetic resonance imaging, confirming pronounced endothelial dysfunction with normal endothelial independent dilatation in PCOS, compared with controls with similar age and BMI. ${ }^{27}$

We reviewed 39 studies that assessed FMD, and 27 (69\%) of them, which included 1,359 patients with PCOS and 1,073 control subjects, showed impaired FMD in PCOS as opposed to 12 studies (including 448 patients with PCOS and 307 control subjects) that did not show any difference between these groups (Table 1).-104 On the contrary, endothelial independent dilatation has been found to be mostly normal in women with PCOS (seven studies with 232 patients with PCOS and 211 control subjects versus three studies with 129 patients with PCOS and 72 controls).

\section{Venous occlusion plethysmography and microvascular function in polycystic ovary syndrome}

Microvascular function can be estimated in resistance arteries, and has been assessed in women with PCOS. In a HEC study in obese women with PCOS, a 50\% reduced endothelial-dependent and insulin-mediated response of leg blood flow was found in the PCOS group, along with resistance to the vasodilating action of insulin, compared with the control group.? This reduction was in response to intrafemoral injection of methacholine chloride. Insulin resistance was suggested to contribute to endothelial dysfunction, whereas BMI and androgens predicted endothelial dysfunction. ${ }^{7}$

Microvascular function has also been assessed, non-invasively, on resistance arteries by VOP on the forearm in women with PCOS who were normoglycaemic, eulipidaemic, and normotensive, compared with controls of comparable age, BMI and waist:hip ratio. ${ }^{21}$ The only parameter that differed between groups was time to peak hyperaemia, a parameter considered to reflect endothelial dysfunction, which was found protracted in the more insulin-resistant women with PCOS. ${ }^{21}$ Interestingly, time-to-peak hyperaemia was negatively related to SHBG, indirect index of hyperinsulinaemia and hyperandrogenaemia. Another study, using the same methodology, confirmed a shorter duration of reactive hyperaemia in the PCOS group, and a significant positive correlation between the duration of reactive hyperaemia and dehydroepiandrosterone-sulfate (DHEAS) levels in the PCOS group was reported, a finding that may support the cardioprotective effect of this androgen. ${ }^{25}$
Young women with PCOS have shown impaired endothelial-dependent dilatation as assessed by blood flow in the microvasculature of the forearm by the water displacement method during insulin infusion into the forearm in insulin-resistant PCOS, whereas insulin-sensitive women with PCOS responded similarly to controls. ${ }^{14}$ On the other hand, vascular function estimated by VOP assessing forearm vasodilatation in response to both endothelium-dependent (acetylcholine/bradykinin) and endothelium-independent (nitroprusside/verapamil) dilatators was not impaired in women with PCOS, compared with age- and weight-matched controls. ${ }^{29}$ Overall, forearm vasodilatation to all four drugs was reduced $(<50 \%)$ in obese women with PCOS, compared with lean women with PCOS, but no significant difference in vascular function was detected between women with PCOS, compared with corresponding controls. On the other hand, obese women with PCOS exhibited markedly reduced vascular smooth muscle function compared with lean subjects with PCOS. ${ }^{29}$ Similarly, using a VOP technique to assess reactive hyperaemia of forearm microcirculation showed no evidence of endothelial dysfunction in obese women with PCOS compared with age- and weight-matched controls with a similar metabolic and inflammatory profile. ${ }^{13}$

Microvascular function has also been studied by wire myography, measuring the concentration response curve to norepinephrine before and after incubation with insulin in young women with PCOS and controls with similar cardiovascular risk factors. ${ }^{8} \mathrm{~A}$ functional defect in the vascular action of insulin ex vivo in patients with PCOS was demonstrated, suggesting a deleterious effect of insulin resistance at a vascular level in women without overt CVD. The defect in resistance arterioles was suggested to be specific to the action of insulin, since constriction to norepinephrine and relaxation to acetylcholine did not differ between women with PCOS and controls. In healthy subjects, insulin caused a dose-related attenuation of norepinephrine action; maximal response and sensitivity to norepinephrine decreased after exposure to physiological and supraphysiological concentrations of insulin. However, no response was observed at physiological doses in the vessels of women with PCOS, whereas at supraphysiological doses, sensitivity, but not maximum response, was altered, suggesting an abnormal resistance artery response to insulin, even in the absence of any other risk factor. ${ }^{8}$

In another study, microvascular function was assessed by forearm skin microvascular erythrocyte flux responses to cumulative iontophoretic doses of $1 \%(\mathrm{~W} / \mathrm{V})$ acetylcholine and $1 \%(\mathrm{~W} / \mathrm{v})$ sodium nitroprusside, using laser Doppler imaging in women with PCOS and age-matched controls. ${ }^{17}$ Basal microvascular perfusion was comparable in PCOS and controls, but the increase in skin microvascular perfusion in response to acetylcholine was blunted and peak acetylcholine-induced erythrocyte flux was reduced in women with PCOS compared with controls. Twenty per cent of acetylcholine response was attributed on insulin and BMI, while altered acetylcholine response was influenced by BMI and androgens levels. No difference in the response to nitrates was documented, implying an exclusively endothelial microvascular dysfunction.

Summarizing, based on different approaches of microcirculation assessment, it could be concluded that women with PCOS have impaired function in micro-vessels, but there are limited data regarding the association of this alteration with the hormonal and metabolic disturbances of the syndrome. On the other hand, among the four studies that have used plethysmography to assess microvasculature, $, 13,21,25$ only one (11 patients with PCOS versus 12 controls) did not show impairment in women with $\mathrm{PCOS}^{13}$ whilst the other three studies 
(66 patients with PCOS versus 53 controls) showed a clear difference ${ }^{7,13,21,25}$ (Table 1). ${ }^{3-104}$ In another two studies performed by the same group where reactive hyperaemia was assessed by an alternative technique, no difference was documented..$^{75,91}$

Another important manifestation to consider as a result of microvascular endothelial dysfunction would be pre-eclampsia, particularly the late-onset, where endothelial involvement has a key role in the pathogenesis. ${ }^{192}$ In fact, a recent prospective cohort study showed that pre-eclampsia, gestational diabetes and lower birth weight among newborns were significantly higher in the women with PCOS compared with healthy controls, identifying higher BMI and hyperandrogenaemia as the strongest predicting factors. ${ }^{193}$

\section{Intima-media thickness and polycystic ovary syndrome}

Intima-media thickness (IMT) is a morphological marker of vascular injury. ${ }^{194}$ An increase in carotid artery IMT has been observed in women with PCOS, and especially in middle-aged women., ${ }^{3,5}$ In 16 premenopausal women, aged $>40$ years old with a history of PCOS, carotid IMT was increased, compared with a control group of similar age. ${ }^{3}$ Nevertheless, this difference was observed between patients and controls, up to the age of 45 and not in younger groups. PCOS was found to represent the unique prognostic factor of variable IMT in multiple regression analyses, while, after correction for age and BMI, the correlations of PCOS changed slightly, implying that part of the observed relation between PCOS and IMT is likely due to central obesity and hyperinsulinaemia. ${ }^{3}$ In a study of 125 women with PCOS and 142 controls, there was a significantly higher prevalence of carotid index of atheromatic plaques in women with PCOS (7.2\% versus $0.7 \%$ ) compared with controls. ${ }^{5}$ The difference in carotid IMT between women with PCOS and controls was detected in women aged $\geq 45$ years, compared with women aged $30-44$ years. Since CVD is characterized by long-term subclinical latency, metabolic disturbances are becoming overt at middle-age only. PCOS and aging appear to interact, resulting in deleterious changes to the carotid arterial wall, since differences in lipids levels between women with PCOS and controls are blunted approaching the menopausal period. ${ }^{194,195}$ As expected, contradictory data have been published in younger women., 9,18,23

Notably, a clinical study investigated the haemodynamic changes in the medial cerebral artery and the internal carotid artery in 28 young women with PCOS and polycystic ovaries (PCO) compared to 24 healthy control subjects. ${ }^{196}$ Blood flow rate and pulsatility index were measured by transcranial Doppler ultrasonography, but no significant differences in haemodynamic parameters were detected between groups. ${ }^{196}$ In another study, impaired carotid IMT in young women of normal weight who were eulipidaemic, normotensive and had PCOS, suggested a premature structural vascular injury.10 In a large-population study, 75 women with PCOS were compared with a group of 55 healthy women of similar age, BMI, smoking habits, familial history for CVD, blood pressure and glucose, and higher IMT values were evidenced in the PCOS group. ${ }^{19}$ In PCOS, IMT was positively correlated with age and BMI and negatively with low HDL-C, DHEAS and androstenedione plasma levels, indicating that adrenal androgens and particularly DHEAS can partially compensate the unfavourable consequence of dyslipidaemia and insulin resistance. This outcome has been supported in other published work, which has focused on the effect on adrenal sex steroids on the metabolic profile of women with PCOS, but did not satisfy the criteria to be included in this review. ${ }^{197,198}$ In fact, in a recent study a positive correlation of 17-hydroxyprogesterone (17-OH-Pg) with HDL-C and HOMA-S was found, which suggests that patients with hyperandrogenaemic PCOS with high levels of 17-OH-Pg could have a certain protection against CVD. ${ }^{199}$ Finally, in 43 young women with PCOS and 43 age-matched controls, common carotid IMT was higher in women with PCOS compared with controls. ${ }^{20}$

Overall, we reviewed 71 studies that assessed IMT; 44 (62\%) of them, including 2,761 patients with PCOS and 2,218 control subjects, showed impairment in PCOS, as opposed to 27 studies (including 1,571 patients with PCOS and 1,286 subjects) that did not show any difference between the groups (Table 1); ${ }^{3-104}$ however, the mixture of population characteristics may have had a major impact on statistics.

\section{Other cardiovascular risk factors}

In a study evaluating serum aldosterone concentration and cardiovascular risk in women with PCOS, a direct correlation between plasma aldosterone, IMT and mean BP was found. Insulin resistance in 50 women with PCOS was positively related to serum aldosterone levels, compared with 50 age- and BMI-matched healthy controls. ${ }^{24}$ The activation of the renin-angiotensin-aldosterone system has an impact on endothelial dysfunction and is involved in the process of atherogenesis in women with PCOS, so spironolactone treatment might reverse endothelial dysfunction in women with PCOS. ${ }^{200}$

\section{Cardiac function and polycystic ovary syndrome}

Other morphological and functional cardiovascular parameters have also been studied in PCOS. An increased prevalence of coronary artery calcium (a marker of coronary atherosclerosis) was found when assessed by non-invasive electron beam computed tomography (EBCT) in 36 women with PCOS, compared with 71 controls of a similar age and BMI. ${ }^{201}$ Similarly, a higher prevalence of coronary artery calcium (45.9\% versus $30.6 \%$ ) and aortic arterial calcification (68.9\% versus 55.3\%), measured by EBCT, was documented in women with PCOS compared with controls in a prospective study, whereby women were screened in 1993-1994 and re-evaluated in 2001-2002..1 After adjustment for age and BMI, PCOS was found to be a significant predictor of coronary artery calcium, but not aortic arterial calcification. In addition, an increased risk of metabolic syndrome was reported in women with PCOS. ${ }^{11}$

In 60 women (20 with PCOS, 20 with PCO and 20 healthy controls), compliance and stiffness indices were assessed in the common and internal carotid arteries using ultrasonographic methods. An impairment was reported in women with PCOS, compared with controls. ${ }^{202}$ Furthermore, macrovascular function at the brachial artery (but not at the aorta), as well as microvascular function, have been found to be impaired, suggesting increased vascular stiffness and a functional defect in the vascular action of insulin ex vivo in patients with PCOS. ${ }^{17}$ This has been confirmed by other studies evaluating arterial stiffness, where insulin resistance was an independent prognostic factor of pulse wave velocity and arterial stiffness in women with PCOS. ${ }^{18}$ Endothelial function has also been assessed using peripheral arterial tonometry methodology, namely a post-ischaemia reactive hyperaemia technique that determines endothelial function as the ratio between the arterial pulse wave amplitude following a 5-minute arterial occlusion in the forearm to the pre-occlusion value, in normal-weight young women with PCOS compared with a control group with similar BMI. ${ }^{30}$ However, taken together, these parameters (arterial stiffness, augmentation index, resistance indices, aortic wave reflections) showed contradictory results (Table 1). ${ }^{3-104}$

Cardiac function parameters have been also investigated in PCOS. In 26 lean young women with PCOS (mean age $22.8 \pm 0.9$ years; mean BMI $23.0 \pm 0.8$ ) and 11 healthy slightly older women with similar BMI (mean age $26.3 \pm 1.7$ years; mean BMl $22.9 \pm 0.9$ ), parameters of 
cardiac output were estimated by ultrasonographic method; impaired parameters of systolic function, as well as their negative association with fasting insulin, were observed in the PCOS group without impairment of diastolic function. ${ }^{179}$ In another study, several diastolic and systolic parameters were impaired in women with PCOS; however, women with PCOS had higher total cholesterol and LDL-C levels compared with controls. ${ }^{180}$ In another study, 30 women with PCOS differed in diastolic cardiac parameters compared with 30 older healthy women, and hyperinsulinaemia and lipidaemic load were higher in the PCOS group. ${ }^{181}$ Another study found that ultrasonographic cardiac parameters were evaluated and women with PCOS had higher left atrium size and left ventricular mass index, lower left ventricular ejection fraction and early-to-late mitral flow velocity ratio than controls.203 When patients and controls were grouped according to weight into normal weight, overweight and obese groups, differences in the metabolic profile and cardiac findings persisted, but a progressive impairment of metabolic profile and echocardiographic pattern was seen in patients with normal weight compared with those with obesity. Young women with PCOS had a significantly increased cardiac size compared with controls, and other structural, systolic and diastolic function cardiac parameters were altered. Notably, most cardiac abnormalities persisted even in young patients with normal weight, suggesting that the pathogenesis of cardiac abnormalities in PCOS is not only dependent on BMI, but also to insulin resistance indices. ${ }^{203}$

Finally, autonomic innervation of the heart, evaluated non-invasively with power spectrum analysis of heart rate variability from electrocardiographic recordings, can be affected in women with PCOS with increased sympathetic and decreased parasympathetic components of heart rate variability. ${ }^{204}$

\section{Biochemical studies for endothelial function assessment in polycystic ovary syndrome}

Endothelial dysfunction can also be assessed biochemically by ET-1 plasma levels measurements. In 2001, Diamanti-Kandarakis et al. showed that ET-1 plasma levels are increased in women with PCOS. ${ }^{6}$ ET-1 plasma levels were positively related to androgen levels and negatively to insulin sensitivity, assessed by HEC (the gold standard assessment of insulin sensitivity), suggesting insulin resistance and hyperinsulinaemia implication in altered endothelial function. These results were later confirmed. ${ }^{10,15}$ Overall, we reviewed seven studies that assessed ET-1 levels, five (71\%) of which included 109 patients with PCOS and 83 controls, and showed increased ET-1 levels in PCOS, whereas two studies (including 59 women with PCOS and 49 controls) did not show any difference between the groups (Table 1). ${ }^{3-104}$

Markers of low-grade inflammation and certain components of the haemostatic system have been also shown to predict atherosclerotic risk in insulin-resistance states such as metabolic syndrome and T2DM. ${ }^{205,206}$ Recent advances in basic science have demonstrated a fundamental role for inflammation in mediating all stages of this disease, from initiation through progression of atherosclerosis. The current notion that inflammation and immune response contribute to atherogenesis has garnered increased interest. ${ }^{207}$ Evidence of low-grade chronic inflammation in PCOS is indicated by the presence of several elevated markers such as CRP levels, 12,177,208,209 inflammatory cytokines, 210-212 increased leukocyte count ${ }^{213}$ and adhesion molecules ${ }^{177}$ (Table 1). ${ }^{3-104}$

A number of studies in humans have assessed the relationship between endothelial function and markers of inflammation, but the results have been variable and sometimes conflicting regarding the relationship between CRP and brachial artery FMD, or between CRP and coronary endothelial dysfunction. In sum, we reviewed 34 studies that assessed CRP levels; 21 (62\%) of them (including 1,589 patients with PCOS and 1,209 control subjects) showed increased CRP levels in PCOS, as opposed to 13 studies (including 591 PCOS and 473 control subjects) that did not show any difference between the groups (Table 1).3-104

\section{Management of endothelial function impairment in polycystic ovary syndrome: Treatment with insulin sensitizers}

A number of mechanisms have been implicated to link endothelial dysfunction with insulin resistance, including disturbances of subcellular signalling pathways to insulin action or other potential unifying links. ${ }^{182,183,214}$ Therefore, utility of insulin sensitizers can be justified in patients with PCOS, and specifically for endothelial function improvement, and we will discuss their function along with other therapeutic agents that have been used for PCOS management (Figure 3).

\section{Metformin}

Metformin is a biguanide agent that has been used in the treatment of T2DM. It lowers blood glucose levels by significantly reducing hepatic glucose production and by increasing peripheral glucose utilization. It lowers serum insulin levels and improves insulin sensitivity, not only by its glucose-lowering effect, but also by increasing insulin-binding to its receptor. ${ }^{215}$ Moreover, the drug appears to enter into the cells and enhance the tyrosine phosphorylation of the intracellular portion of $\beta$-subunit of the insulin receptor and of insulin receptor substrate (IRS) proteins. ${ }^{216}$ Recently, it has been suggested that IRS genotype may modulate the response to metformin treatment in women with PCOS. ${ }^{217}$

A number of studies have been published investigating the effect of metformin on insulin resistance in women with PCOS. One study showed that metformin treatment in 26 obese women with PCOS for 2 months reduced hyperinsulinaemia and systolic BP, and improved hormonal and reproductive abnormalities. ${ }^{218}$ The first European study, published in 1998, confirmed the increase in insulin sensitivity (glucose utilization rate) using the $\mathrm{HEC}$, irrespective of the changes in body weight, after administration of 1,700 mg metformin for 6 months in 13 obese women with PCOS. ${ }^{219}$ Metformin has been shown to improve lipid profile, mainly by increasing serum HDL-C concentrations. ${ }^{220,221}$ However, some studies have shown only a negligible or no effect on lipids in women with PCOS. ${ }^{218,222}$ The mechanisms by which metformin improves lipid profile are not clear; it has been suggested to reduce lipid uptake or synthesis in the intestine and in the hepatocytes. ${ }^{220,223}$ The improvement of obesity, especially abdominal obesity, with a subsequent decreased release of free fatty acids from adipose tissue observed during metformin therapy could also partly explain the improvement of lipid profile during metformin treatment, at least in obese women. ${ }^{224}$

A study investigating the effect of metformin on endothelial function in obese and non-obese women with PCOS and increased plasma ET-1 levels, revealed a statistically significant reduction of those levels in both groups after 6 months of treatment. ${ }^{6}$ Interestingly, hyperandrogenaemia, as well as insulin resistance (assessed by $\mathrm{HEC}$ ), were improved in parallel with ET-1 levels post-metformin without a concomitant reduction in BMI. Later, the administration of 1,700 mg metformin daily for 6 months in young overweight women with PCOS normalized FMD on the brachial artery, and at the same time significantly decreased ET-1 plasma levels..$^{15}$ On the other hand, when metformin was used for 3 months, no improvement was observed in endothelial function assessed using peripheral arterial tonometry methodology in normal-weight 


Metformin
$\downarrow$ Blood glucose
$\downarrow$ Gluconeogenesis
$\downarrow$ Insulinaemia
$\downarrow$ IR ( $\downarrow$ glucose, $\uparrow$ ins receptor)
$\downarrow$ BP
$\downarrow$ Lipid uptake/synthesis, FFAs
$\downarrow$ ET-1
$\downarrow$ LoW-grade chronic inflammation
$\downarrow$ CRP
$\downarrow$ Adhesion molecules
$\downarrow$ AGES
$\downarrow$ Microvascular function
$\downarrow$ Coronary flow reserve
$\downarrow$ VCAM-1/ICAM-1
$\uparrow$ HDL-C
Normalize FMD
Improve FMD
Improve IMT
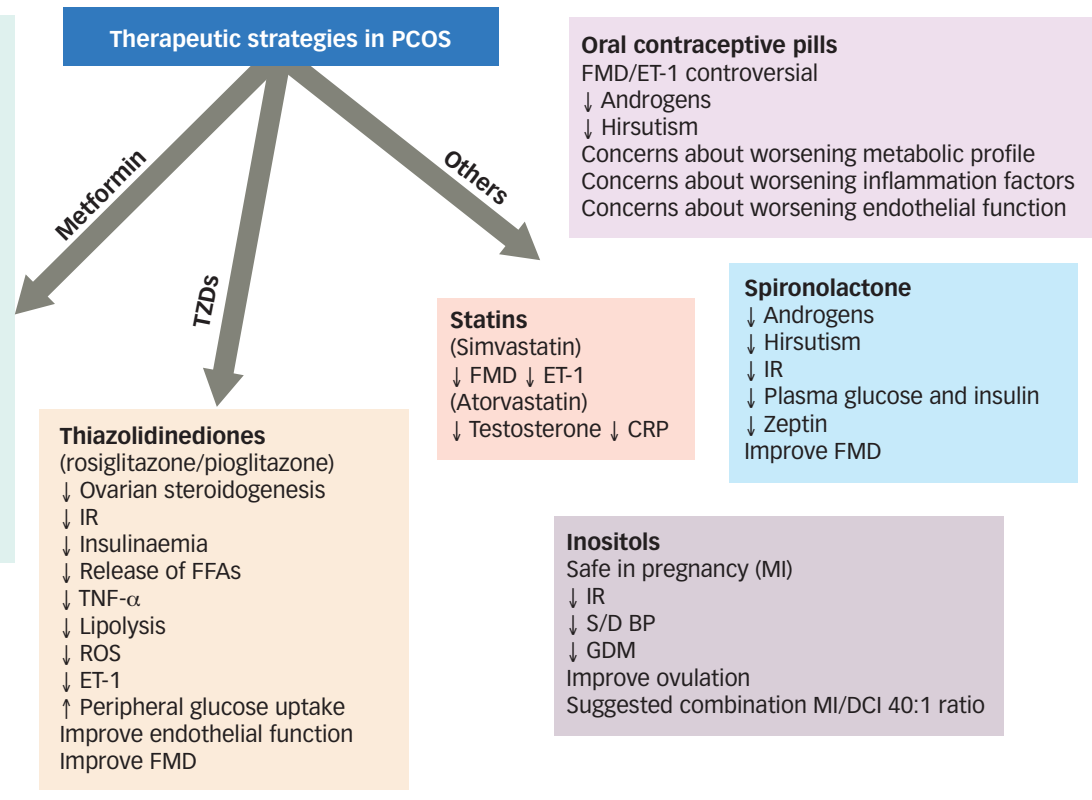

Inositols
Safe in pregnancy (MI)
$\downarrow$ IR
$\downarrow$ S/D BP
$\downarrow$ GDM
Improve ovulation
Suggested combination $\mathrm{MI} / \mathrm{DCl}$ 40:1 ratio

$\downarrow$ decreased/reduced; $\uparrow$ increased.

AGES = advanced glycated end-products; $B P=$ blood pressure; $C R P=C$-reactive protein; $D C l=D$-chiro-inositol; ET-1 = endothelin 1; FFAS = free fatty acids; FMD = flow-mediated dilatation; GDM = gestational diabetes mellitus; $H D L-C=$ high-density lipoprotein cholesterol; ICAM-1 = Intercellular adhesion molecule 1; IMT = intima-media thickness; ins = insulin; $I R=$ insulin resistance; $M I=$ myo-inositols; $P C O S=$ polycystic ovary syndrome; $R O S=$ reactive oxygen species; $S / D=s y s t o l i c / d i a s t o l i c ;$ TNF- $\alpha$ : tumour necrosis factor $\alpha$; TZDS = thiazolidinediones; VCAM-1 = vascular cell adhesion protein 1.

young women with PCOS. ${ }^{30}$ The exact mechanism, direct or indirect, by which metformin acts on endothelium, has not been clarified. Nevertheless, metformin treatment has been associated with a significant decrease of low-grade chronic inflammatory markers. ${ }^{177}$

In a randomized study, a significant reduction in serum CRP levels by $31 \%$ was shown in non-obese patients and $56 \%$ in obese patients, post-metformin administration. ${ }^{225}$ Adhesion molecules have also been reduced after 6 months of treatment with metformin in 62 patients with PCOS, independently of body weight changes. ${ }^{177}$ In addition, AGEs, a complex and heterogeneous potent atherogenic group of molecules, 226 and their receptors, were found to be elevated in young women with PCOS. ${ }^{178}$ Although the mechanism implicated in this phenomenon is not clear, it could be due to insulin action defects; dietary-exogenous AGEs may also contribute to it. ${ }^{227}$ Metformin administration for 6 months reduced, but did not normalize, AGEs serum levels compared with pre-treatment levels; this effect of metformin, if confirmed, could be of clinical significance in improving adverse long-term sequelae of the syndrome. ${ }^{228}$ Metformin was also administered in women with PCOS with and without insulin resistance, and improved microvascular function and coronary flow reserve after 6 months, as assessed by transthoracic second-harmonic Doppler echocardiographic methodology. ${ }^{229}$

We reviewed metformin administration in 19 study groups, in a total number of 465 women with PCOS for a median period of 6 months' time (range 3-6 months). Oral contraceptive pills were co-administered in two studies. FMD improved (increased) in 8 out of 10 (80\%) studies, ET-1 improved (decreased) in all the four studies in which this was assessed, IMT improved (decreased) in 8 out of 10 (80\%) studies, and amelioration in reactive hyperaemia in two out of the three studies in which this was assessed. These findings indicate the beneficial effect that metformin exerts on micro-, macro-circulation as well as on the structural arterial properties of young women with PCOS (Table 2). ${ }^{15,35,4,4,57,58,63,68,77,86,87,9,9,96,101,104-125}$ In contrast,
CRP levels were not reduced in five out of six (83\%) studies, 35,63,7,7,86,116 not confirming the documented anti-inflammatory action of metformin on this low-grade inflammation present in this young population. $35,63,7,7,86,10,117$

\section{Thiazolidinediones}

Thiazolidinediones include three drugs: troglitazone, rosiglitazone and pioglitazone. They act by enhancing glucose uptake in adipose and muscle tissues. In comparison to the effect observed by metformin, thiazolidinediones increase more peripheral glucose uptake and decrease lesser hepatic glucose output. They improve insulin sensitivity and they decrease not only circulating insulin but also the release of free fatty acids and TNF- $\alpha$ from adipose tissue. At the cellular level they bind and activate the peroxisome proliferator activated receptor- $\gamma$ (PPAR- $\gamma$ ) and they induce the transcription of genes that are involved in glucose control and lipid metabolism. ${ }^{230}$

In women with PCOS, the therapeutic effect of insulin sensitizers is mediated by the reduction of hyperinsulinaemia and insulin resistance, and consequently by alteration of ovarian steroidogenesis. Moreover, an inhibitory effect in steroidogenesis has been demonstrated on humanized yeast cells, and thiazolidinediones (rosiglitazone and pioglitazone) have been found to inhibit estradiol and testosterone production in cultured human ovarian cells. ${ }^{231}$ Dunaif was the first to study the effects of troglitazone on metabolic profile in women with PCOS in a double-blind, randomized, 3-month trial of two doses (200 mg, 400 mg) of troglitazone.232 Hyperinsulinaemia, as well as insulin sensitivity, was assessed by a frequently sampled intravenous glucose tolerance test and improved significantly.

In a later study, troglitazone was administrated for 3 months in 13 obese women with PCOS and found to have impaired endothelial function, as assessed by leg blood flow responses to graded intrafemoral artery infusion of the endothelium-dependent vasodilator methacholine chloride. Basal leg blood flow was found unchanged after troglitazone, 
but the increase in leg blood flow in response to methacholine chloride in PCOS was markedly more pronounced after treatment and was similar to that observed in obese women without PCOS. ${ }^{233}$ It was suggested that troglitazone improves endothelial function by reducing lipolysis, reactive oxygen species production, ${ }^{234}$ ET-1 secretion ${ }^{235}$ or vascular inflammation. ${ }^{236}$ Confirming the above results, as troglitazone was retracted from clinical use, rosiglitazone was administered in 31 young normal to overweight women with PCOS for 1 year and it was observed to improve endothelial function, and at the same time, insulin sensitivity indices, hyperandrogenaemia, hyperinsulinaemia and systemic inflammation, when assessed by CRP. ${ }^{237}$

Overall, in two of the included studies, where rosiglitazone was given for a median time of 4.5 months (range 3-6 months), FMD was improved, but not NID, in one study, ${ }^{107}$ and in the second study using a different method to assess microcirculation, no improvement was noted in endothelial-dependent function as opposed to a significant improvement in endothelial-independent function. ${ }^{119}$ On the contrary, in the study of 14 women with PCOS with pioglitazone administration, FMD was improved. ${ }^{57}$

\section{Other agents}

\section{Oral contraceptive pills}

Oral contraceptive pills represent a traditional treatment for the hyperandrogenic sequelae of women with PCOS. We reviewed 13 study groups of women with PCOS receiving oral contraceptives, who were compared, or not, with other treatments. Metformin was co-administered in two of the studies included. FMD improved in three (27\%) out of 11 study-groups; ET-1 levels did not improve in one study where this was assessed; whilst IMT improved in three (33\%), but deteriorated in one out of nine study groups (Table 2). ${ }^{15,35,4,4,57,58,63,6,7,7,8,8,87,91,96,101,104-125}$ Similarly, CRP levels were not reduced in all four study groups that assessed it. A meta-analysis including three randomized controlled studies that compared oral contraceptives containing oestrogen (ethinylestradiol) with progestogen drospirenone or chlormadinone acetate, showed a beneficial effect of ethinylestradiol/drospirenone over ethinylestradiol/chlormadinone acetate in reducing androstenedione levels and total testosterone after 3 months, and Ferriman-Gallwey score after 6 months. ${ }^{238}$

Although oral contraceptive pills improve clinical and biochemical hyperandrogenism, there are concerns about worsening the metabolic and inflammatory profile of these patients. Adipokines, such as adiponectin, visfatin and resistin, which are considered indices of both inflammation and insulin resistance, have deteriorated in women with PCOS after 6 months of oral contraceptive treatment compared with controls. ${ }^{239}$ Additionally, the use of oral contraceptives in obese and non-obese patients with PCOS with impaired glucose tolerance increases asymmetric dimethylarginin, which is a marker of endothelial dysfunction and CRP levels, so creates an increase in metabolic risk. ${ }^{240}$ On the other hand, the combination of oral contraceptive pills with metformin in overweight women with PCOS may lower this risk, as it seems to improve both hyperandrogenism and inflammatory parameters. ${ }^{241}$ Similar results have been shown when metformin has been combined with anti-androgens containing oral contraceptives, which may improve androgen and insulin resistance. However, this addition of metformin has achieved a reduction in adhesion molecules as markers of low-grade chronic endothelial inflammation and CVD. ${ }^{242}$

\section{Statins and glucagon-like peptide-1}

Statins have been also investigated in PCOS. Atorvastatin failed to improve FMD but reduced CRP in nine women with PCOS in only 6 weeks, ${ }^{114}$ whereas simvastatin given for 6 months improved FMD and hormonal profile, and reduced ET-1 levels. ${ }^{96,243}$ Liraglutide has also been trialled for a 6-month period, but no overt benefits were seen in reactive hyperaemic index, IMT, CRP and adhesion molecules.91 Although, the reproductive and hyperandrogenaemic profile of these patients was not examined in these studies, a very recent meta-analysis of nine randomized controlled trials (613 patients) showed a superiority of atorvastatin compared with all other treatments (simvastatin, spironolactone, oral contraceptives and metformin) to reduce total testosterone levels in patients with PCOS. ${ }^{244}$

\section{Spironolactone}

Spironolactone, due to its anti-androgenic and aldosterone antagonistic effects, has been explored among PCOS treatment strategies. It has been shown to be effective in improving both reproductive and metabolic parameters, equally to pioglitazone and superiorly to metformin, especially when combined with high doses of vitamin $D$ supplementation. ${ }^{245}$ Thirty non-obese patients with PCOS with normal mean aldosterone plasma levels had significantly lower FMD compared with 20 BMI-matched control subjects, but this difference was reversed after 6 months' therapy with spironolactone. ${ }^{115}$

\section{Inositols}

Inositols are polyols with insulin-sensitizing properties. Myo-inositol is the most common naturally occurring stereoisomer, which can be converted to a second stereoisomer, D-chiro-inositol (DCl). Inositols are involved in insulin signalling, with both myo-inositol and DCl functioning as insulin second messengers, although they mediate different actions of insulin in humans. Specifically, myo-inositol is considered safe in pregnancy and beneficial in reducing insulin resistance, systolic/diastolic BP and the risk of gestational diabetes, which have a higher incidence among women with PCOS. ${ }^{246}$ The clinical experience with DCl is inferior to myo-inositol, but more interesting data are being published regarding the combination of the two. A recent meta-analysis evaluated the efficacy of treatments with myo-inositol, alone or combined with $\mathrm{DCl}$ (40:1 ratio between myo-inositol and DCl) for 12-24 weeks, in nine randomized controlled trials comprising 247 cases and 249 controls. Significant improvement in metabolic parameters (insulin levels, HOMA-IR), and to a lesser extent testosterone levels, was seen after inositol supplementation. ${ }^{247}$ Moreover, the combination of myo-inositol and $\mathrm{DCl}$ in a 40:1 ratio seems to improve the reproductive profile of these patients by restoring ovulation in 62.5\%. ${ }^{248}$ The synergistic effect of metformin with myo-inositol, as opposed to metformin alone, was also investigated in women with PCOS undergoing ovulation induction, and showed not only an increase in live birth rate, but also an improvement in insulin sensitivity and reduced requirements for metformin dosage. ${ }^{249}$

\section{General considerations}

Taken altogether, controversial data exist regarding the presence of endothelial dysfunction and arterial structure impairment in women with PCOS, with certain studies reporting no impairment and others showing significant alterations. Differences in cardiovascular risk factors (principally differences in metabolic profile between patients and controls) among the various populations studied might explain these discrepancies. However, endothelial dysfunction seems to be a well-recognized trait of PCOS in both micro-and macro-circulation, although not all the investigators agree.

Regarding the pathophysiology of the phenomenon, it has been postulated that insulin-resistant individuals exhibit resistance to both the metabolic and vascular actions of insulin. PI3K, a key intracellular signalling step of insulin action, has been shown by in vivo studies 
to be defective in the insulin-resistant state, as well as in PCOS. ${ }^{141}$ The signalling pathways by which insulin mediates glucose uptake and nitric oxide production converge at the PI3K/AKt. ${ }^{182,250}$ Consequently, disruption of this pathway may link different pathogenic mechanisms, leading to impaired glucose utilization and endothelial dysfunction. Furthermore, hyperinsulinaemia drives ET-1 production by endothelial cells via the PI3K pathway, further impairing endothelial function by competing with NO; ET-1 has been shown to inhibit insulin signalling via the same pathway. ${ }^{183,214}$ ET-1 levels have been found increased in women with PCOS. ${ }^{6}$ These findings support the hypothesis that, in women with PCOS, the abnormal vasculature status could be due to impaired insulin vasodilator functions, mediated by PI3K. ${ }^{251}$

On the other hand, there are data that support a role of hyperandrogenaemia in vascular reactivity in PCOS, but the mode of action of androgens remains unknown. Androgen receptors are known to exist on the vessel wall, and a direct effect of androgens in the vasculature cannot be excluded. ${ }^{252}$ Alternatively, androgens may act synergistically with insulin resistance, ${ }^{253}$ inflammatory cytokines ${ }^{177,254}$ or angioconstrictive peptides ${ }^{6}$ on endothelial function. Androgens may promote monocyte adhesion to endothelial cells, a proatherogenic effect mediated, at least in part, by increased endothelial vascular cell adhesion protein-1 (VCAM-1) expression, ${ }^{255}$ which has been found elevated in women with PCOS. ${ }^{26}$ There are also some interesting data favouring a compensatory role of adrenal androgens and particularly DHEAS for the adverse effects of dyslipidaemia and insulin resistance. ${ }^{19}$

Recently, correlations between various cardiovascular risk factors, insulin resistance, hyperandrogenaemia, endothelial dysfunction and chronic inflammation have been detected in PCOS populations, supporting the concept of their interplay on the vascular bed pathophysiology of women with PCOS. ${ }^{26}$ Whether these interactions could contribute to long-term sequelae, namely in CVD events, has not been clarified. Nevertheless, the principal candidates' effectors for cardiovascular risk factors and for endothelial dysfunction presence remain insulin resistance and hyperandrogenaemia, the basal characteristics of PCOS.

Hypotheses for endothelial dysfunction pathogenesis also implicate a number of additional atherogenic molecules. Increased expression of soluble intercellular adhesion molecule-1 and soluble VCAM-1 found in patients with PCOS 26,177 plays an important role in focal leukocyte accumulation in subendothelial regions of atheroma:;254,255 however the causes of elevated inflammatory molecules remain unclear. ${ }^{26}$ The associations between chronic inflammation and endothelial dysfunction with features of PCOS, such as obesity, ${ }_{1}^{256,257}$ may have an additional aggravating role. On the other hand, high testosterone levels have been found to induce VCAM-1 expression.

The central role of insulin resistance and hyperandrogenaemia can also be certified by the beneficial effects of the action of insulin sensitizers on the endothelium, since those agents improve those pathogenic effectors. Recent studies make efforts to shed light on mechanisms of action of insulin-sensitizing agents on the endothelium. Notably, in one study, metformin was shown to improve endothelial function, by lowering atherogenic molecules, like adhesion molecules ${ }^{177}$ or AGEs serum. ${ }^{228}$ It has been suggested that metformin has an inhibitory effect in the glycation process ${ }^{258-260}$ by interfering with the synthetic pathway of AGEs through the trapping of methyl-glyoxal and of other dicarbonyl compounds responsible for the glycation process in vivo. ${ }^{261}$ Therefore, the action of metformin may lead to reduced synthesis and/or increased detoxification of AGE metabolites. ${ }^{262,263}$ Regarding the clearance of AGES, intact PI3K activity is required for the activation of the macrophage scavenger receptor, which is one of the major mechanisms for their clearance. ${ }^{264} \mathrm{PI} 3 \mathrm{~K}$, a key intracellular signalling step of insulin action, has been shown to be defective in an insulin-resistant state and in PCOS. ${ }^{141}$ The decreased PI3K activity present in insulin-resistant PCOS may link the pathogenic mechanisms of PCOS insulin resistance with decreased AGE clearance. ${ }^{141}$ Nevertheless, a mechanism independent from the antihyperglycaemic effect has been shown for metformin in preventing microvascular alterations. ${ }^{265}$

Inositols also have insulin-sensitizing properties that may be proved to be of clinical significance, with or without metformin co-administration. ${ }^{249}$ However, FMD has been improved by spironolactone administration alone as opposed to its co-administration with oral contraceptive pills, where no improvement was seen in 6 months in the context of FMD, carotid artery stiffness index and IMT; whereas at 12 months, a deterioration in IMT was observed. ${ }^{118}$ Notably, the combination of oral contraceptives, drospirenone and metformin for 6 months resulted in FMD improvement, possibly due to the impact of metformin. ${ }^{116}$ However, the addition of drospirenone in oral contraceptives also improved FMD but deteriorated IMT without alteration of CRP levels, implying an ill-defined role for drospirenone. ${ }^{68}$

Finally, lifestyle amendments, such as a structured exercise training programme, heat therapy, carnitine or vitamin administration, as well as laparoscopic ovarian drilling, improved FMD and/or IMT, implying that the role of lifestyle changes or hormonal control are necessary for a better cardiovascular risk-factor profile. 87,122,123-125 $^{2}$

\section{Conclusion}

It can be concluded that endothelial dysfunction is more likely to occur among patients with PCOS than in healthy controls. In order to confirm this widely accepted observation, there is a need for large-scale, well-designed prospective studies of cardiovascular outcomes in PCOS for a better understanding of the role that the cardinal features of PCOS, insulin resistance and hyperandrogenaemia may have on vascular function. Long-term cohort studies are particularly needed in the different phenotypes of PCOS, in order to provide information for the target-to-treat in each phenotype, since different modes of treatments may be used in different sub-phenotypes with differences in the cardiometabolic or reproductive risk profile of the syndrome.

Since, there are no universal specific diagnostic signs or characteristic phenotypes that could preclude the response to different therapeutic modalities, it seems important to assess the predominant symptoms and risk factors in the metabolic and reproductive aspects of each woman, with the aim of producing individualized treatments. Based on the pathophysiological role of insulin resistance, insulin-sensitizing agent administration can be justified, particularly as a treatment of choice in hyperinsulinaemic obese or non-obese women. Other interventions, such as lipid-lowering agents, antioxidants, oral contraceptives and anti-androgen agents have to be further investigated in order to assess their role as therapeutic tools in PCOS management, since their effects on the cardiovascular properties in PCOS are missing.

Finally, large-scale, long-term follow-up studies should be designed based on the established cardiovascular risk factors in order to identify the best clinical and biochemical markers that could be used in clinical practice for the prevention of a potentially 'silent' trigger of CVD, which can occur early in life, masked behind hormonal and reproductive signs and symptoms. $\square$ 
1. Diamanti-Kandarakis E, Kouli CR, Bergiele AT, et al. A survey of the polycystic ovary syndrome in the Greek island of Lesbos: hormonal and metalic profile $J$ Clin Endocrinol Metab. 1999:84:4006-11.

2. Diamanti-Kandarakis $E$, Dunaif A. New perspectives in polycystic ovary syndrome. Trends Endocrinol Metab. 1996; 7:267-71.

3. Guzick DS, Talbott EO, Sutton-Tyrrell K, et al. Carotid atherosclerosis in women with polycystic ovary syndrome: initial results from a case-control study. Am J Obstet Gynecol. 1996;174:1224-9.

4. Mather KJ, Verma S, Corenblum B, Anderson TJ. Normal endothelial function despite insulin resistance in healthy women with the polycystic ovary syndrome. J Clin Endocrinol Metab. 2000;85:1851-6.

5. Talbott EO, Guzick DS, Sutton-Tyrrell K, et al. Evidence for association between polycystic ovary syndrome and premature carotid atherosclerosis in middle-aged women. Arterioscler Thromb Vasc Biol. 2000;20:2414-21.

6. Diamanti-Kandarakis E, Spina G, Kouli C, Migdalis I. Increased endothelin-1 levels in women with polycystic ovary syndrome and the beneficial effect of metformin therapy. $J$ Clin Endocrinol Metab. 2001;86:4666-73.

7. Paradisi G, Steinberg HO, Hempfling A, et al. Polycystic ovary syndrome is associated with endothelial dysfunction. Circulation. 2001;103:1410-5

8. Kelly CJ, Speirs A, Gould GW, et al. Altered vascular function in young women with polycystic ovary syndrome. I Clin Endocrinol Metab. 2002;87:742-6.

9. Lakhani K, Hardiman P, Seifalian AM. Intima-media thickness of elastic and muscular arteries of young women with polycystic ovaries. Atherosclerosis. 2004;175:353-9.

10. Orio F Jr, Palomba S, Cascella T, et al. Early impairment of endothelial structure and function in young normal-weight women with polycystic ovary syndrome. I Clin Endocrinol Metab. 2004:89:4588-93.

11. Talbott EO, Zborowski JV, Rager JR, et al. Evidence for an association between metabolic cardiovascular syndrome and coronary and aortic calcification among women with polycystic ovary syndrome. J Clin Endocrinol Metab. 2004;89:5454-61.

12. Tarkun I, Arslan BC, Cantürk Z, et al. Endothelial dysfunction in young women with polycystic ovary syndrome: relationship with insulin resistance and low-grade chronic inflammation. J Clin Endocrinol Metab. 2004;89:5592-6.

13. Bickerton AS, Clark N, Meeking D, et al. Cardiovascular risk in women with polycystic ovarian syndrome (PCOS). J Clin Pathol. 2005;58:151-4.

14. Carmassi F, De Negri F, Fioriti R, et al. Insulin resistance causes impaired vasodilation and hypofibrinolysis in young women with polycystic ovary syndrome. Thromb Res. 2005;116:207-14.

15. Diamanti-Kandarakis E, Alexandraki K, Protogerou A, et al. Metformin administration improves endothelial function in Motformin administration improves endothelial function in women with polycystic $2005: 152: 749-56$.

16. Kravariti M, Naka KK, Kalantaridou SN, et al. Predictors of endothelial dysfunction in young women with polycystic ovary syndrome. J Clin Endocrinol Metab. 2005;90:5088-95.

17. Lakhani K, Leonard A, Seifalian AM, Hardiman P. Microvascular dysfunction in women with polycystic ovary syndrome. Hum Reprod. 2005;20:3219-24.

18. Meyer C, McGrath BP, Teede HJ. Overweight women with polycystic ovary syndrome have evidence of subclinic cardiovascular disease. I Clin Endocrinol Metab. 2005;90:5711-6.

19. Vryonidou A, Papatheodorou A, Tavridou A, et al. Association of hyperandrogenemic and metabolic phenotype with carotid intima-media thickness in young women with polycystic ovary syndrome. J Clin Endocrinol Metab. 2005:90:2740-6.

20. Vural $B$, Caliskan E, Turkoz E, et al. Evaluation of metabolic syndrome frequency and premature carotid atherosclerosis in young women with polycystic ovary syndrome. Hum Reprod. 2005:20:2409-13.

21. Alexandraki K, Protogerou A, Papaioannou T, et al. Early microvascular and macrovascular dysfunction is not accompanied by structural arterial injury in polycystic ovary syndrome. Hormones (Athens). 2006;5:126-36

22. Brinkworth GD, Noakes M, Moran $\sqcup$, et al. Flow-mediated dilatation in overweight and obese women with polycystic ovary syndrome. BJOG. 2006;113:1308-14.

23. Carmina E, Orio F, Palomba S, et al. Endothelial dysfunction in PCOS: role of obesity and adipose hormones. Am J Med. 2006:119:356.e1-6.

24. Cascella T, Palomba S, Tauchmanovà L, et al. Serum aldosterone concentration and cardiovascular risk in women with polycystic ovarian syndrome. J Clin Endocrinol Metab. 2006:91:4395-400.

25. Dagre A, Lekakis J, Mihas C, et al. Association of dehydroepiandrosterone-sulfate with endothelial function in young women with polycystic ovary syndrome Eur J Endocrinol. 2006:154:883-90.

26. Diamanti-Kandarakis E, Alexandraki K, Piperi C, et al. Inflammatory and endothelial markers in women with polycystic ovary syndrome. Eur J Clin Invest. 2006;36:691-7.

27. Sorensen MB, Franks S, Robertson C, et al. Severe endothelial dysfunction in young women with polycystic ovary syndrome is only partially explained by known cardiovascular risk factors. Clin Endocrinol (Oxf). 2006:65:655-9.

28. Beckman JA, Goldfine AB, Dunaif $A$, et al. Endothelial function varies according to insulin resistance disease type. Diabetes Care. 2007:30:1226-32.

29. Dokras A, Jagasia DH, Maifeld M, et al. Obesity and insulin resistance but not hyperandrogenism mediates vascular dysfunction in women with polycystic ovary syndrome. Fertil Steril. 2006:86:1702-9.

30. Lowenstein L, Damti A, Pillar G, et al. Evaluation of endothelial function in women with polycystic ovary syndrome. Eur J Obstet Gynecol Reprod Biol. 2007;134:208-12.

31. Luque-Ramírez M, Mendieta-Azcona C, Alvarez-Blasco F,
Escobar-Morreale HF. Androgen excess is associated with the increased carotid intima-media thickness observed in young women with polycystic ovary syndrome. Hum Reprod. 2007;22:3197-203

32. Cascella T, Palomba S, De Sio I, et al. Visceral fat is associated with cardiovascular risk in women with polycystic ovary syndrome. Hum Reprod. 2008;23:153-9.

33. Erdoğan M, Karadeniz M, Alper GE, et al. Thrombin-activatable fibrinolysis inhibitor and cardiovascular risk factors in polycystic ovary syndrome. Exp Clin Endocrinol Diabetes. 2008;116:143-7.

34. Trakakis E, Balanika A, Baltas C, et al. Hemodynamic alteration and wall properties in large arteries of young, normotensive, and non-obese women with polycystic ovary syndrome. J Endocrinol Invest. 2008:31:1001-7.

35. Heutling D, Schulz H, Nickel I, et al. Asymmetrical dimethylarginine, inflammatory and metabolic parameters in women with polycystic ovary syndrome before and after metformin treatment. J Clin Endocrinol Metab. 2008;93:82-90.

36. Karadeniz M, Erdogan M, Zengi A, et al. Polymorphism of the interleukin-10 gene in polycystic ovary syndrome. interleukin-10 gene in polycystic ovary
Int I Immunogenet 2008:35:119-23.

37. Adali $E$, Yildizhan $R$, Kurdoglu M, et al. Increased plasma thrombin-activatable fibrinolysis inhibitor levels in young obese women with polycystic ovary syndrome. Fertil Steril. 2010;94:666-72

38. Arikan S, Akay H, Bahceci M, et al. The evaluation of endothelial function with flow-mediated dilatation and carotid intima media thickness in young nonobese polycystic ovary syndrome patients; existence of insulin resistance alone may not represent an adequate condition for deterioration of endothelial function. Fertil Steril. 2009;91:450-5.

39. Carmina E, Guastella E, Longo RA, et al. Correlates of increased lean muscle mass in women with polycystic ovary syndrome. Eur J Endocrinol. 2009;161:583-9.

40. Ciccone MM, Favales, Bhuva A et al Anteroposterio diameter of the infrarenal abdominal aorta is higher in women with polycystic ovary syndrome. Vasc Health Risk Manag. 2009;5:561-6.

41. Cussons AJ, Watts GF, Stuckey BG. Dissociation of endothelial function and arterial stiffness in nonobese women with polycystic ovary syndrome (PCOS). Clin Endocrinol (Oxf). 2009;71:808-14.

42. Erdogan M, Karadeniz M, Berdeli A, et al. The relationship of the interleukin-6-174 G>C gene polymorphism with cardiovascular risk factors in Turkish polycystic ovary syndrome patients. Int J Immunogenet. 2009:36:283-8.

43. Kaya C, Erkan AF, Cengiz SD, et al. Advanced oxidation protein products are increased in women with polycystic ovary syndrome: relationship with traditional and nontraditiona syndrome: relationship with traditional and nontraditional
cardiovascular risk factors in patients with polycystic ovary syndrome. Fertil Steril. 2009:92:1372-7.

44. Luque-Ramírez M, Mendieta-Azcona C, del Rey Sánchez $\mathrm{JM}$, et al. Effects of an antiandrogenic oral contraceptive pil compared with metformin on blood coagulation tests and endothelial function in women with the polycystic ovary syndrome: influence of obesity and smoking. Eur J Endocrinol. 2009;160:469-80

45. Mancini F, Cianciosi A, Reggiani GM, et al. Endothelial function and its relationship to leptin, homocysteine, and insulin resistance in lean and overweight eumenorrheic women and PCOS patients: a pilot study. Fertil Steril. 2009;91:2537-44.

46. Moran L, Hutchison SK, Meyer C, et al. A comprehensive assessment of endothelial function in overweight women with and without polycystic ovary syndrome. Clin SCi (Lond). 2009;116:761-70

47. Soares GM Vieira CS, Martins WP et al Increased arteria stiffness in nonobese women with polycystic ovary syndrome (PCOS) without comorbidities: one more characteristic inherent to the syndrome? Clin Endocrinol (Oxf). 2009;71:406-11.
8. Costa LO, dos Santos MP, Oliveira M, Viana A. Low-grade 8. Costa LO, dos Santos MP, Oliveira M, Viana A. Low-grade
chronic inflammation is not accompanied by structural arterial injury in polycystic ovary syndrome. Diabetes Res Clin Pract. 2008;81:179-83.

49. Kaya C, Pabuccu R, Berker B, Satiroglu H. Plasma interleukin-18 levels are increased in the polycystic ovary syndrome: relationship of carotid intima-media wall thickness and cardiovascular risk factors. Fertil Steril. 2010:93:1200-7.

50. Ketel IJ, Stehouwer CD, Henry RM, et al. Greater arterial stiffness in polycystic ovary syndrome (PCOS) is an obesity--but not 2010;95:4566-75.

51. Battaglia C Battaglia B Mancini F et al. Ultrasonographic extended-view technique for evaluation of abdominal fat distribution in lean women with polycystic ovary syndrome. Acta Obstet Gynecol Scand. 2011;90:600-8.

52. Caglar GS, Oztas E, Karadag D, et al. Ischemia-modified albumin and cardiovascular risk markers in polycystic ovary syndrome with or without insulin resistance. Fertil Steril. 2011;95:310-3.

53. Cakir E, Ozbek M, Ozkaya E, et al. Oxidative stress markers are not valuable markers in lean and early age of polycystic ovary syndrome patients. J Endocrinol Invest. 2011;34:e178-82.

54. Coksuer H, Koplay M, Oghan F, et al. Evaluation of carotid wall thickness and vertebro-basilar system insufficiency in patients with obese polycystic

55. Ercan EA, Ertek S, IS G, et al. Factors associated with increased carotid intima-media thickness and being nondipper in nonobese and normotensive young patients affected by PCOS Angiology. 2011;62:543-8.

56. Mohammadi A, Aghasi M, Jodeiry-Farshbaf L, et al. Evaluation of early atherosclerotic findings in women with polycystic ovary syndrome. J Ovarian Res. 2011;4:19.

57. Naka KK, Kalantaridou SN, Kravariti M, et al. Effect of the insulin sensitizers metformin and pioglitazone on endothelial function in young women with polycystic ovary syndrome: a prospective

randomized study. Fertil Steril. 2011;95:203-9.

. Naka KK Kalantaridou SN Bechlioulis A et al. Effect of ethinylestradiol/cyproterone acetate on endothelial function in young non-obese women with polycystic ovary syndrome: a pilot study. Gynecol Endocrinol. 2011;27:615-21.

59. Pamuk B Torun A Kulaksizoglu M et al Asymmetric dimethylarginine levels and carotid intima-media thickness in obese patients with polycystic ovary syndrome and their relationship to metabolic parameters. Fertil Steril. 2010;93:1227-33.

60. Pepene CE, Ilie IR, Marian I, Duncea I. Circulating osteoprotegerin and soluble receptor activator of nuclear factor $\mathrm{\kappa B}$ ligand in polycystic ovary syndrome: relationships to insulin resistance and endothelial dysfunction. Eur J Endocrinol. 2011;164:61-8

61. Soyman Z, Noyan V, Tulmac M, et al. Serum paraoxonase 1 activity, asymmetric dimethylarginine levels, and brachial artery flow-mediated dilatation in women with polycystic ovary syndrome. Fertil Steril. 2011;95:1067-72.

62 Studen KB, Sebestien M, Pfeifer M, Prezelj J. Influence of spironolactone treatment on endothelial function in non-obese women with polycystic ovary syndrome. Eur J Endocrinol. 2011;164:389-95

63. Tan BK, Adya R, Shan X, et al. The anti-atherogenic aspect of metformin treatment in insulin resistant women with the polycystic ovary syndrome: role of the newly established pro-inflammatory adipokine Acute-phase Serum Amyloid A; evidence of an adipose tissue-monocyte axis. Atherosclerosis. 2011;216:402-8

64. Cakir E, Ozbek M, Sahin M, et al. Heart type fatty acid binding protein response and subsequent development of atherosclerosis in insulin resistant polycystic ovary syndrome patients. J Ovarian Res. 2012;5:45.

65. Cakir E, Doğan M, Topaloglu O, et al. Subclinical atherosclerosis and hyperandrogenemia are independent risk factors for increased epicardial fat thickness in patients with PCOS and idiopathic hirsutism. Atherosclerosis. 2013;226:291-5.

66. Karabulut A, Yaylali GF, Demirlenk S, et al. Evaluation of body fat distribution in PCOS and its association with carotid atherosclerosis and insulin resistance. Gynecol Endocrinol. 2012;28:111-4.

67. Karoli R, Fatima J, Siddiqi Z, et al. Study of early atherosclerotic markers in women with polycystic ovary syndrome. Indian J Endocrinol Metab. 2012;16:1004-8.

68. Pepene CE. Soluble platelet/endothelial cell adhesion molecule (SPECAM)-1 is increased in polycystic ovary syndrome and related to endothelial dysfunction. Gynecol Endocrinol. 2012;28:370-4

69. Pepene CE. Evidence for visfatin as an independent predictor of endothelial dysfunction in polycystic ovary syndrome Clin Endocrinol (Oxf). 2012;76:119-25.

70. Zueff LF Martins WP Vieira CS, Ferriani RA. Ultrasonographic and laboratory markers of metabolic and cardiovascular disease risk in obese women with polycystic ovary syndrome Ultrasound Obstet Gynecol. 2012;39:341-7.

71. Abali R, Celik C, Tasdemir N, et al. The serum protein $\alpha 2$-Heremans-Schmid glycoprotein/fetuin-a concentration and carotid intima-media thickness in women with polycystic ovary syndrome. Eur J Obstet Gynecol Reprod Biol. 2013;169:45-9.

72. Allameh Z, Rouholamin S, Adibi A, et al. Does carotid intima-media thickness have relationship with polycystic ovary syndrome? Int J Prev Med. 2013;4:1266-70.

73. Barcellos CR, Lage SH, Rocha MP, et al. Polycystic ovary syndrome and obesity do not affect vascular parameters related to early atherosclerosis in young women without glucose metabolism disturbances, arterial hypertension and gevere abnormalities of lipid profile. Gynecol Endocrinol. 2013;29:370-4.

74. Celik $C$, Bastu E, Abali R, et al. The relationship between copper, homocysteine and early vascular disease in lean women with polycystic ovary syndrome. Gynecol Endocrinol. 2013;29:488-91

75. Kahal H, Aburima A, Ungvari T, et al. Polycystic ovary syndrome has no independent effect on vascular, inflammatory or thrombotic markers when matched for obesity. Clin Endocrinol (OXf). 2013;79:252-8.

76. Kim JJ, Choi YM, Kang JH, et al. Carotid intima-media thickness in mainly non-obese women with polycystic ovary syndrome and age-matched controls. Obstet Gynecol Sci. 2013;56:249-55

77. Tan BK, Chen J, Hu J, et al. Metformin increases the novel adipokine cartonectin/CTRP3 in women with polycystic ovary syndrome. J Clin Endocrinol Metab. 2013;98:E1891-900. 
marker for arginine vasopressin, is associated with cardiovascular risk in patients with polycystic ovary syndrome. J Ovarian Res. 2014;7:31.

85. Rees E, Coulson R, Dunstan F, et al. Central arterial stiffness and diastolic dysfunction are associated with insulin resistance and abdominal obesity in young women but polycystic ovary syndrome does not confer additional risk. Hum Reprod. 2014;29:2041-9

86. Tan BK, Chen J, Hu J, et al. Circulatory changes of the novel adipokine adipolin/CTRP12 in response to metformin treatmen and an oral glucose challenge in humans. Clin Endocrinol (Oxf). 2014;81:841-6.

87. Shokeir T, El-Kannishy G. The effects of laparoscopic ovarian drilling on flow mediated dilation in women with PCOS: relationship with insulin resistance and IGF-I. Minerva Ginecol. 2014;66:209-18

88. Sprung VS, Jones $\mathrm{H}$, Pugh CJ, et al. Endothelial dysfunction in hyperandrogenic polycystic ovary syndrome is not explained by either obesity or ectopic fat deposition. Clin Sci (Lond). 2014:126:67-74.

89. Abali R, Tasdemir N, Alpsoy S, et al. No relationship between osteoprotegerin concentrations and endothelial dysfunction in non-obese women with and without polycystic ovary syndrome. Arch Gynecol Obstet. 2015;291:1075-80.

90. Aldrighi JM, Tsutsui JM, Kowastch I, et al. Effects of insulin resistance on myocardial blood flow and arterial peripheral circulation in patients with polycystic ovary syndrome. Echocardiography. 2015;32:1277-84.

91. Kahal $\mathrm{H}$, Aburima A, Ungvari T, et al. The effects of treatment with liraglutide on atherothrombotic risk in obese young women with polycystic ovary syndrome and controls. BMC Endocr Disord. 2015;15:14.

92. Macut $\mathrm{D}$, Bačević M, Božić-Antić I, et al. Predictors of subclinical cardiovascular disease in women with polycystic ovary syndrome: interrelationship of dyslipidemia and arterial blood pressure Int J Endocrinol 2015:2015:812610.

93. Taskin MI, Bulbul E, Adali E, et al. Circulating levels of obestatin and copeptin in obese and nonobese women with polycystic ovary syndrome. Eur J Obstet Gynecol Reprod Biol. 2015; 189:19-23

94. Yilmaz SA, Kebapcilar A, Koplay M, et al. Association of clinical androgen excess with radial artery intima media thickness in women with polycystic ovary syndrome. Gynecol Endocrinol. 2015;31:477-82.

95. Gursoy Calan O, Calan M, Yesil Senses P, et al. Increased adipsin is associated with carotid intima media thickness and metabolic disturbances in polycystic ovary syndrome. Clin Endocrinol (Oxf). 2016;85:910-7.

96. Yang B, Sun ZJ, Chen B, et al. Statin ameliorates endothelia dysfunction and insulin resistance in Tibet women with polycystic ovary syndrome. Eur Rev Med Pharmacol SC 2016:20:1185-91

97. Bicer M, Guler A, Unal Kocabas G, et al. Endocan is a predictor of increased cardiovascular risk in women with polycystic ovary syndrome. Endocr Res. 2017;42:145-53.

98. Ramoglu S, Yoldemir T, Atasayan K, Yavuz DG. Does cardiovascular risk vary according to the criteria for a diagnosis of polycystic ovary syndrome? J Obstet Gynaecol Res. 2017;43:1848-54.

99. Tripathy P, Sahu A, Sahu M, Nagy A. Ultrasonographic evaluation of intra-abdominal fat distribution and study of its influence on subclinical atherosclerosis in women with polycystic ovarian syndrome. Eur I Obstet Gynecol Reprod Biol 2017:217:18-22.

100. Calan M, Guler A, Unal Kocabas G, et al. Association of kallistatin with carotid intima-media thickness in women with polycystic ovary syndrome. Minerva Endocrino. 2018:43:236-45.

101. Wang $H H$, Lin $M$, Xiang GD. Serum HMGB1 levels and its association with endothelial dysfunction in patients with polycystic ovary syndrome. Physiol Res. 2018;67:911-9.

102. Bicer M, Alan M, Alarslan P, et al. Circulating insulin-like peptide 5 levels and its association with metabolic and hormonal parameters in women with polycystic ovary syndrome. J Endocrinol Invest. 2019;42:303-12.

103. Rashad NM, El-Shal AS, Abomandour HG, et al. Intercellular adhesion molecule-1 expression and serum levels as markers of pre-clinical atherosclerosis in polycystic ovary syndrome. J Ovarian Res. 2019:12:97.

104. Alexandraki K, Kandaraki E, Papaioannou T, et al. Assessment of aortic wave reflection in lean and obese women with polycystic ovary syndrome. Archives of the Balkan Medical Union. 2020:5:11-19.

105. Orio F Jr. Palomba S, Cascella T, et al. Improvement in endothelial structure and function after metformin treatment in young normal-weight women with polycystic ovary syndrome: results of a 6-month study. J Clin Endocrinol Metab.

106. Sahin Y, Unluhizarci $K$, Yilmazsoy A, et al. The effects of metformin on metabolic and cardiovascular risk factors in nonobese women with polycystic ovary syndrome. Clin Endocrinol (Oxf). 2007;67:904-8.

107. Jensterle M, Sebestjen M, Janez A, et al. Improvement of endothelial function with metformin and rosiglitazone treatment in women with polycystic ovary syndrome. Eur J Endocrinol. 2008;159:399-406.

108. Romualdi D, Costantini B, Selvaggi L, et al. Metformin improves endothelial function in normoinsulinemic PCOS patients: a new endothelial function in normoinsulinemic PCOS
prospective. Hum Reprod. 2008;23:2127-33

109. Luque-Ramírez M, Mendieta-Azcona C, Alvarez-Blasco F, Escobar-Morreale HF. Effects of metformin versus ethinyl-estradiol plus cyproterone acetate on ambulatory blood pressure monitoring and carotid intima media thickness in women with the polycystic ovary syndrome. Fertil Steril. 2009;91:2527-36.

110. Tan BK, Adya R, Chen J, et al. Metformin decreases angiogenesis via NF-kappaB and Erk1/2/Erk5 pathways by creasing the antiangiogenic thrombospondin-1. Cardiovasc Res. 2009:83:566-74.

111. Mancini F, Cianciosi A, Persico N, et al. Drospirenone and cardiovascular risk in lean and obese polycystic ovary syndrome patients: a pilot study. Am J Obstet Gynecol. 2010:202:169.e1-8.

112. Palomba S, Falbo A, Giallauria F, et al. Effects of metformin with or without supplementation with folate on homocysteine level and vascular endothelium of women with polycystic ovary
syndrome. Diabetes Care. 2010;33:246-51.

113. Gode F, Karagoz C, Posaci C, et al. Alteration of cardiovascular risk parameters in women with polycystic ovary syndrome who were prescribed to ethinyl estradiol-cyproterone acetate. Arch Gynecol Obstet. 2011;284:923-9.

114. Raja-Khan N, Kunselman AR, Hogeman CS, et al. Effects of atorvastatin on vascular function, inflammation, and androgens in women with polycystic ovary syndrome: a double-blind, randomized, placebo-controlled trial. Fertil Steril. 2011;95:1849-52.

115. Baiuk Studen K, Jensterle Sever M. Pfeifer M. Cardiovascular risk and subclinical cardiovascular disease in polycystic ovary syndrome Front Horm Res. 2013:40:64-82.

116. Ilie IR, Marian I, Mocan T, et al. Ethinylestradiol30ug-drospirenone and metformin: could this combination improve endothelial dysfunction in polycystic ovary syndrome? BMC Endocr Disord. 2012;12:9.

17. Karabulut A, Demirlenk S, Sevket O. Effects of ethinyl estradiol-cyproterone acetate treatment on metabolic syndrome, fat distribution and carotid intima media thickness in polycystic ovary syndrome. Gynecol Endocrinol. 2012;28:245-8.

118. Vieira CS, Martins WP, Fernandes JB, et al. The effects of 2 mg chlormadinone acetate/30 mcg ethinylestradiol, alone or combined with spironolactone, on cardiovascular risk markers in women with polycystic ovary syndrome. Contraception. 2012:86:268-75.

119. Mohiyiddeen L, Watson AJ, Apostolopoulos NV, et al. Effects of low-dose metformin and rosiglitazone on biochemical, clinical, metabolic and biophysical outcomes in polycystic ovary syndrome. J Obstet Gynaecol. 2013;33:165-70.

120. Sprung VS, Cuthbertson DJ, Pugh CJ, et al. Exercise training in polycystic ovarian syndrome enhances flow-mediated dilation in the absence of changes in fatness. Med Sci Sports Exerc. 2013;45:2234-42.

121. Kaya MG, Yildirim S, Calapkorur B, et al. Metformin improves endothelial function and carotid intima media thickness in patients with PCOS. Gynecol Endocrinol. 2015;31:401-5.

122. Orio F, Muscogiuri G, Giallauria F, et al. Oral contraceptives versus physical exercise on cardiovascular and metabolic risk factors in women with polycystic ovary syndrome: a randomized controlled trial. Clin Endocrinol (Oxf). 2016;85:764-71.

123. Ely BR, Francisco MA, Halliwill JR, et al. Heat therapy reduces sympathetic activity and improves cardiovascular risk profile in obese women with polycystic ovary syndrome. Am J Physiol Regul Integr Comp Physiol. 2019;317:R630-40.

124. Talari HR, Poladchang S, Hamidian Y, et al. The effects of omega-3 and vitamin e co-supplementation on carotid intima-media thickness and inflammatory factors in patients with polycystic ovary syndrome. Oman Med J. 2018;33:473-9.

125. Talari HR, Azad ZJ, Hamidian Y, et al. Effects of carnitine administration on carotid intima-media thickness and inflammatory factors in patients with polycystic ovary syndrome: A randomized, double-blind, placebo-controlled trial. Int J Prev Med. 2019;10:89.

126. Stein I, Leventhal M. Amenorrhoea associated with bilatera polycystic ovaries. Am J Obstet Gynecol. 1935;29:181-91.

127. Diamanti-Kandarakis $\mathrm{E}$ Kandarakis $\mathrm{H}$, Legro RS. The role of genes and environment in the etiology of PCOS. Endocrine. 2006;30:19-26

128. Azziz R, Carmina E, Dewailly D, et al. The Androgen Excess and PCOS Society criteria for the polycystic ovary syndrome: th complete task force report. Fertil Steril. 2009;91:456-88.

29. Diamanti-Kandarakis E, Panidis D. Unravelling the phenotypic map of polycystic ovary syndrome (PCOS): a prospective stud of 634 women with PCOS. Clin Endocrinol. 2007;67:735-42.

30. Dunaif A. Insulin resistance and the polycystic ovary syndrome: mechanism and implications for pathogenesis. Endocr Rev. 1997; $18: 774-800$

31. Wild RA. Long-term health consequences of PCOS. Hum Reprod Update. 2002;8:231-41.

132. Legro RS. Polycystic ovary syndrome and cardiovascular disease: a premature association? Endocr Rev. 2003;24:302-12

133. National Cholesterol Education Program (NCEP) Exper Panel on Detection, Evaluation, and Treatment of High Blood Cholesterol in Adults (Adult Treatment Panel III). Third report of the National Cholesterol Education Program (NCEP) Expert Panel on Detection, Evaluation, and Treatment of High Blood Cholesterol in Adults (Adult Treatment Panel III) final report.
Circulation. 2002;106:3143-421.

134. Sam S, Dunaif A. Polycystic ovary syndrome: syndrome XX? Trends Endocrinol Metab. 2003;14:365-70.

135. Glueck CJ, Papanna R, Wang P, et al. Incidence and treatment of metabolic syndrome in newly referred women with confirmed polycystic ovarian syndrome. Metabolism. 2003;52:908-15,

136. Apridonidze T, Essah PA, luorno MJ, Nestler JE. Prevalence and characteristics of the metabolic syndrome in women with polycystic ovary syndrome. I Clin Endocrinol Metab. 2005;90:1929-35.

137. Chang RJ, Nakamura RM, Judd HL, Kaplan SA. Insulin resistance in nonobese patients with polycystic ovarian disease. J Clin Endocrinol Metab. 1983;57:356-9.

138. Dunaif A, Segal KR, Futterweit W, Dobrjansky A. Profound peripheral insulin resistance, independent of obesity, in polycystic ovary syndrome. Diabetes. 1989;38:1165-74.

139. Book CB, Dunaif A. Selective insulin resistance in the polycystic ovary syndrome. I Clin Endocrinol Metab. 1999;84:3110-6.

140. Dunaif $A$, Xia J, Book CB, et al. Excessive insulin receptor serine phosphorylation in cultured fibroblasts and in skeletal muscle. A potential mechanism for insulin resistance in the polycystic ovary syndrome. J Clin Invest. 1995:96:801-10.

141. Dunaif A, WU X, Lee A, Diamanti-Kandarakis E. Defects in insulin receptor signaling in vivo in the polycystic ovary syndrome (PCOS). Am J Physiol Endocrinol Metab. 2001;281:E392-9.

142. Diamanti-Kandarakis E, Kouli C, Alexandraki K, Spina G. Failure of mathematical indices to accurately assess insulin resistance in lean, overweight, or obese women with polycystic ovary syndrome. J Clin Endocrinol Metab. 2004;89:1273-6.

143. Polak K, Czyzyk A, Simoncini T, Meczekalski B. New markers of insulin resistance in polycystic ovary syndrome. J Endocrinol Invest. 2017:40:1-8.

144. Moghetti P, Tosi F, Bonin C, et al. Divergences in insulin resistance between the different phenotypes of the polycystic ovary syndrome. J Clin Endocrinol Metab. 2013;98:E628-37.

145. Kirchengast S, Huber J. Body composition characteristics and body fat distribution in lean women with polycystic ovary syndrome. Hum Reprod. 2001:16:1255-60.

146. Balen AH, Conway GS, Kaltsas G, et al. Polycystic ovary syndrome: the spectrum of the disorder in 1741 patients. Hum Reprod. 1995;10:2107-11.

147. Knochenhauer ES, Key TJ, Kahsar-Miller M, et al. Prevalence of the polycystic ovary syndrome in unselected black and white women of the southeastern United States: a prospective study. J Clin Endocrinol Metab. 1998;83:3078-82.

148. Talbott E, Guzick D, Clerici A, et al. Coronary heart disease risk factors in women with polycystic ovary syndrome. Arterioscler Thromb Vasc Biol. 1995;15:821-6.

149. Strowitzki T, Halser B, Demant T. Body fat distribution, insulin sensitivity, ovarian dysfunction and serum lipoproteins in patients with polycystic ovary syndrome. Gynecol Endocrinol 2002;16:45-51.

150. Kirchengast S, Huber J. Body composition characteristics and fat distribution patterns in young infertile women. Fertil Steril. 2004;81:539-44

151. Legro RS, Kunselman AR, Dodson WC, Dunaif A. Prevalence and predictors of risk for type 2 diabetes mellitus and impaired glucose tolerance in polycystic ovary syndrome: a prospective, controlled study in 254 affected women. $J$ Clin Endocrinol Metab. 1999;84:165-9.

152. Ehrmann DA, Barnes RB, Rosenfield RL, et al. Prevalence of impaired glucose tolerance and diabetes in women with polycystic ovary syndrome. Diabetes Care. 1999:22:141-6.

153. Setji TL, Holland ND, Sanders LL, et al. Nonalcoholic steatohepatitis and nonalcoholic fatty liver disease in young women with polycystic ovary syndrome. J Clin Endocrinol Metab. 2006;91:1741-7.

154. Vgontzas AN, Legro RS, Bixler EO, et al. Polycystic ovary syndrome is associated with obstructive sleep apnea and daytime sleepiness: role of insulin resistance. J Clin Endocrinol Metab. 2001:86:517-20.

155. Dahlgren E, Janson PO, Johansson S, et al. Polycystic ovary syndrome and risk for myocardial infarction. Evaluated from a risk factor model based on a prospective population study of women. Acta Obstet Gynecol Scand. 1992;71:599-604.

6. Ross R. The pathogenesis of atherosclerosis: a perspective for the 1990s. Nature. 1993;362:801-9.

157. Lobo RA, Carmina E. The importance of diagnosing the polycystic ovary syndrome. Ann Intern Med. 2000;132:989-93.

158. Birdsall MA, Farquhar CM, White HD. Association between polycystic ovaries and extent of coronary artery disease in women having cardiac catheterization. Ann Intern Med. 1997;126:32-5.

159. Legro RS, Kunselman AR, Dunaif A. Prevalence and predictors of dyslipidemia in women with polycystic ovary syndrome. Am J Med. 2001:111:607-13.

160. O'Meara NM, Blackman JD, Ehrmann DA, et al. Defects in beta-cell function in functional ovarian hyperandrogenism. J Clin Endocrinol Metab. 1993;76:1241-7.

161. Ovalle F, Azziz R. Insulin resistance, polycystic ovary syndrome, and type 2 diabetes mellitus. Fertil Steril. 2002;77:1095-105.

162. Laws A, Reaven GM. Insulin resistance and risk factors for coronary heart disease. Baillieres Clin Endocrinol Metab. 1993; 7:1063-78

163. Elting MW, Korsen TJ, Bezemer PD, Schoemaker J. Prevalence of diabetes mellitus, hypertension and cardiac complaints in a follow-up study of a Dutch PCOS population 
J Clin Endocrinol Metab. 1991;72:83-9.

172. Jayagopal V, Kilpatrick ES, Jennings PE, et al. The biological variation of testosterone and sex hormone-binding globulin (SHBG) in polycystic ovarian syndrome: implications for SHBG as a surrogate marker of insulin resistance I Clin Endocrinol Metab. 2003:88:1528-33.

173. Ducluzeau PH, Cousin P, Malvoisin E, et al. Glucose-to-insulin ratio rather than sex hormone-binding globulin and adiponecti levels is the best predictor of insulin resistance in nonobese women with polycystic ovary syndrome. I Clin Endocrinol Metab. 2003;88:3626-31

174. Mingrone G, Greco AV, Giancaterini A, et al. Sex hormone-binding globulin levels and cardiovascular risk factors in morbidly obese subjects before and after weight reduction induced by diet or malabsorptive surgery. Atherosclerosis. 2002;161:455-62

175. Arcaro G, Cretti A, Balzano S, et al. Insulin causes endothelia dysfunction in humans: sites and mechanisms. Circulation. 2002;105:576-82.

176. Diamanti-Kandarakis E, Palioniko G, Alexandraki K, et al. The prevalence of $4 \mathrm{G} 5 \mathrm{G}$ polymorphism of plasminogen activato inhibitor-1 (PAl-1) gene in polycystic ovarian syndrome and its association with plasma PAl-1 levels. Eur J Endocrinol. 2004;150:793-8

177. Diamanti-Kandarakis E, Paterakis T, Alexandraki K, et al. Indices of low-grade chronic inflammation in polycystic ovary syndrome and the beneficial effect of metformin. Hum Reprod. 2006;21:1426-31

178. Diamanti-Kandarakis E, Piperi C, Kalofoutis A, Creatsas G. Increased levels of serum advanced glycation end-products in women with polycystic ovary syndrome. Clin Endocrinol (OXf). 2005;62:37-43

179. Prelevic GM, Beljic T, Balint-Peric L, Ginsburg J. Cardiac flow velocity in women with the polycystic ovary syndrome Clin Endocrinol (Oxf). 1995;43:677-81.

180. Tíras MB, Yalcin R, Noyan V, et al. Alterations in cardiac flow parameters in patients with polycystic ovarian syndrome Hum Reprod. 1999:14:1949-52.

181. Yarali $H$, Yildirir A, Aybar F, et al. Diastolic dysfunction and increased serum homocysteine concentrations may contribute to increased cardiovascular risk in patients with polycystic ovary syndrome. Fertil Steril. 2001;76:511-6.

182. Wheatcroft SB, Williams IL, Shah AM, Kearney MT. Pathophysiological implications of insulin resistance on vascular endothelial function. Diabet Med. 2003;20:255-68.

183. Jiang ZY, Zhou QL, Chatterjee A, et al. Endothelin-1 modulates insulin signaling through phosphatidylinositol 3-kinase pathway in vascular smooth muscle cells. Diabetes. 1999;48:1120-30.

184. Verma S, Anderson TJ. Fundamentals of endothelial function for the clinical cardiologist. Circulation. 2002;105:546-9.

185. Gokce N, Keaney JF Jr, Hunter LM, et al. Risk stratification for postoperative cardiovascular events via noninvasive assessment of endothelial function: a prospective study. Circulation. 2002;105:1567-72.

186. McVeigh GE, Brennan GM, Johnston GD, et al. Impaired endothelium-dependent and independent vasodilation in patients with type 2 (non-insulin-dependent) diabetes mellitus. Diabetologia. 1992;35:771-6.

87. Hsueh WA, Lyon CJ, Quiñones MJ. Insulin resistance and the endothelium. Am J Med. 2004;117:109-17.

188. Alexandraki K, Piperi C, Kalofoutis C, et al. Inflammatory process in type 2 diabetes: the role of cytokines. Ann N Y Acad SC. 2006;1084:89-117.

189. Corretti MC, Anderson TJ, Benjamin EJ, et al. Guidelines for the ultrasound assessment of endothelial-dependent flow-mediated vasodilation of the brachial artery: a report of the International Brachial Artery Reactivity Task Force. the International Brachial Artery Re

190. Anderson TJ, Uehata A, Gerhard MD, et al. Close relation of endothelial function in the human coronary and periphera circulations. J Am Coll Cardiol. 1995;26:1235-41.

191. Schächinger V, Britten MB, Zeiher AM. Prognostic impact of coronary vasodilator dysfunction on adverse long-term outcome of coronary heart disease. Circulation. 2000;101:1899-906.

192. Burton GJ, Redman CW, Roberts JM, Moffett A. Pre-eclampsia: pathophysiology and clinical implications. BMJ. 2019:366:12381

193. Foroozanfard F, Asemi Z, Bazarganipour F, et al. Comparing pregnancy, childbirth, and neonatal outcomes in women with different phenotypes of polycystic ovary syndrome and healthy women: a prospective cohort study. Gynecol Endocrinol. 2020;36:61-5

194. O'Leary DH, Polak JF, Kronmal RA, et al. Carotid-artery intima and media thickness as a risk factor for myocardial infarction and stroke in older adults. Cardiovascular Health Study

195. Sir-Petermann T, Angel B, Maliqueo M, et al. Prevalence of type II diabetes mellitus and insulin resistance in parents of women with polycystic ovary syndrome. Diabetologia. 2002;45:959-64.

196. Kizkin S, Engin-Ustun Y, Ustun Y, et al. Cerebral artery hemodynamics in polycystic ovary syndrome. Gynecol Endocrinol. 2005:21:287-91.

197. Alpañés M, Luque-Ramírez M, Martínez-García M, et al. Influence of adrenal hyperandrogenism on the clinical and metabolic phenotype of women with polycystic ovary syndrome. Fertil Steril. 2015;103:795-801.e2.

198. Goodarzi MO, Carmina E, Azziz R. DHEA, DHEAS and PCOS. J Steroid Biochem Mol Biol. 2015;145:213-25.

199. de Medeiros SF, Ormond CM, de Medeiros MAS, et al. Metabolic and endocrine connections of 17-hydroxypregnenolone in polycystic ovary syndrome women. Endocr Connect. 2017;6:479-88.

00. Macut D, Mladenović V, Bjekić-Macut J, et al. Hypertension in polycystic ovary syndrome: novel insights. Curr Hypertens Rev.
2020;16:55-60.

201. Christian RC, Dumesic DA, Behrenbeck T, et al. Prevalence and predictors of coronary artery calcification in women with polycystic ovary syndrome. J Clin Endocrinol Metab. 2003:88:2562-8.

202. Lakhani K, Seifalian AM, Hardiman P. Impaired carotid viscoelastic properties in women with polycystic ovaries Circulation. 2002:106:81-5.

203. Orio F Jr, Palomba S, Spinelli L, et al. The cardiovascular risk of young women with polycystic ovary syndrome: an observational, analytical, prospective case-control study. J Clin Endocrinol Metab. 2004;89:3696-701.

204. Yildirir A, Aybar F, Kabakci G, et al. Heart rate variability in young women with polycystic ovary syndrome. Ann Noninvasive Electrocardiol. 2006;11:306-12.

205. Ridker PM, Hennekens CH, Buring JE, Rifai N. C-reactive protein and other markers of inflammation in the prediction of cardiovascular disease in women. $N$ Eng/ I Med. 2000;342:836-43.

206. Danesh J, Wheeler JG, Hirschfield GM, et al. C-reactive protein and other circulating markers of inflammation in the prediction of coronary heart disease. N Eng/ J Med. 2004:350:1387-97.

207 . Libby P, Ridker PM, Maseri A. Inflammation and atherosclerosis. Circulation. 2002;105:1135-43.

208. Kelly CC, Lyall H, Petrie JR, et al. Low grade chronic nflammation in women with polycystic ovarian syndrome. J Clin Endocrinol Metab. 2001;86:2453-5.

209. Boulman N, Levy Y, Leiba R, et al. Increased C-reactive protein levels in the polycystic ovary syndrome: a marker of cardiovascular disease. J Clin Endocrinol Metab. 2004;89:2160-5.

210. Escobar-Morreale H, Villuendas G, Botella-Carretero J, et al. Obesity, and not insulin resistance, is the major determinant of serum inflammatory cardiovascular risk markers in pre-menopausal women. Diabetologia. 2003;46:625-33.

211. Escobar-Morreale HF, Botella-Carretero II, Villuendas G, et al. Serum interleukin- 18 concentrations are increased in the polycystic ovary syndrome: relationship to insulin resistance and to obesity I Clin Endocrinol Metab. 2004:89:806-11.

212. Gonzalez F, Thusu K, Abdel-Rahman E, et al. Elevated serum levels of tumor necrosis factor alpha in normal-weight women with polycystic ovary syndrome. Metabolism. 1999;48:437-41.

13. Orio F Jr, Palomba S, Cascella T, et al. The increase of leukocytes as a new putative marker of low-grade chronic inflammation and early cardiovascular risk in polycystic ovary syndrome. J Clin Endocrinol Metab. 2005;90:2-5.

214. Harrison DG. Cellular and molecular mechanisms of endothelia cell dysfunction. J Clin Invest. 1997:100:2153-7.

215. Bailey Cl. Metformin an update Gen Pharmacol. 1993;24:1299-309

216. Wiernsperger NF, Bailey $C J$. The antihyperglycaemic effect of metformin: therapeutic and cellular mechanisms. Drugs. 1999;58(Suppl. 1):31-9.

217. Ertunc D, Tok EC, Aktas A, et al. The importance of IRS-1 Gly972Arg polymorphism in evaluating the response to metformin treatment in polycystic ovary syndrome Hum Reprod. 2005;20:1207-12

218. Velazquez EM, Mendoza S, Hamer T, et al. Metformin therapy in polycystic ovary syndrome reduces hyperinsulinemia, insulin resistance, hyperandrogenemia, and systolic blood pressure while facilitating normal menses and pregnancy. Metabolism. 1994;43:647-54

219. Diamanti-Kandarakis E, Kouli C, Tsianateli T, Bergiele A. Therapeutic effects of metformin on insulin resistance and hyperandrogenism in polycystic ovary syndrome. Eur J Endocrinol. 1998:138:269-74.

220. Rautio K, Tapanainen IS, Ruokonen A Morin-Papunen LC Effects of metformin and ethinyl estradiol-cyproterone acetate on lipid levels in obese and non-obese women with polycystic ovary syndrome. Eur J Endocrinol. 2005:152:269-75.

221. Moghetti P, Castello R, Negri C, et al. Metformin effects on clinical features, endocrine and metabolic profiles, and insulin sensitivity in polycystic ovary syndrome: a randomized, double-blind, placebo-controlled 6-month trial, followed by open, long-term clinical evaluation. J Clin Endocrinol Metab. 2000;85:139-46

222. Ehrmann DA, Cavaghan MK, Imperial J, et al. Effects of metformin on insulin secretion, insulin action, and ovarian steroidogenesis in women with polycystic ovary syndrome. I Clin Endocrinol Metab. 1997;82:524-30.

223. Weng S, Luo Y, Zhang Z, et al. Effects of metformin on blood lipid profiles in nondiabetic adults: a meta-analysis of randomized controlled trials Endocrine 2020:67:305-17.

224. Pasquali R Gambineri A Biscotti D et al. Effect of long-term treatment with metformin added to hypocaloric diet on body composition, fat distribution, and androgen and insulin levels in abdominally obese women with and without the polycystic ovary syndrome. J Clin Endocrinol Metab. 2000:85:2767-74.

225. Morin-Papunen L, Rautio K, Ruokonen A, et al. Metformin reduces serum C-reactive protein levels in women with polycystic ovary syndrome. J Clin Endocrinol Metab. 2003;88:4649-54

226. Vlassara H, Bucala R, Striker L. Pathogenic effects of advanced glycosylation: biochemical, biologic, and clinical implications for diabetes and aging. Lab Invest. 1994;70:138-51.

227. Diamanti-Kandarakis E, Piperi C, Alexandraki K, et al. Short-term effect of orlistat on dietary glycotoxins in healthy women and women with polycystic ovary syndrome. Metabolism. 2006:55:494-500.

228. Diamanti-Kandarakis E, Alexandraki K, Piperi C, et al. Effect of metformin administration on plasma advanced glycation end product levels in women with polycystic ovary syndrome .

229. Topcu S, Tok D, Caliskan M, et al. Metformin therapy improves coronary microvascular function in patients with polycystic

vary syndrome and insulin resistance. Clin Endocrinol (OXf). $2006 ; 65: 75-80$

230. Henry RR. Thiazolidinediones. Endocrinol Metab Clin North Am. 1997;26:553-73.

231. Seto-Young D, Paliou M, Schlosser t, et al. Direct thiazolidinedione action in the human ovary: insulin-independent and insulin-sensitizing effects on steroidogenesis and insulin-like growth factor binding proteinproduction. J Clin Endocrinol Metab. 2005;90:6099-105.

32. Dunaif A, Scott D, Finegood D, et al. The insulin-sensitizing agent troglitazone improves metabolic and reproductive abnormalities in the polycystic ovary syndrome. J Clin Endocrinol Metab. 1996;81:3299-306.

233. Paradisi G, Steinberg HO, Shepard MK, et al. Troglitazone therapy improves endothelial function to near normal levels in women with polycystic ovary syndrome. J Clin Endocrinol Metab. 2003;88:576-80.

234. Garg R, Kumbkarni Y, Aljada A, et al. Troglitazone reduces reactive oxygen species generation by leukocytes and lipid peroxidation and improves flow-mediated vasodilatation in obese subjects. Hypertension. 2000;36:430-5.

235. Satoh $\mathrm{H}$ Tsukamoto $\mathrm{K}$. Hashimoto $\mathrm{Y}$ et al. Thiazolidinediones suppress endothelin-1 secretion from bovine vascular endothelial cells: a new possible role of PPARgamma on vascular endothelial function. Biochem Biophys Res Commun. 1999;254:757-63.

236. Pistrosch F, Passauer J, Fischer S, et al. In type 2 diabetes, osiglitazone therapy for insulin resistance ameliorates endothelial dysfunction independent of glucose control. Diabetes Care. 2004;27:484-90.

237. Tarkun I, Cetinarslan B, Türemen E, et al. Effect of rosiglitazone on insulin resistance, C-reactive protein and endothelial function in non-obese young women with polycystic ovary syndrome. Eur J Endocrinol. 2005:153:115-21.

238. Menshawy A, Ismail A, Abdel-Maboud M, et al. Effect of chlormadinone acetate versus drospirenone-containing oral contraceptives on the endocrinal features of women with polycystic ovary syndrome: systematic review and meta-analysis of randomized clinical trials. J Gyneco Obstet Hum Reprod. 2019;48:763-70.

239. Manzoor S, Ganie MA, Amin S, et al. Oral contraceptive use increases risk of inflammatory and coagulatory disorders in women with polycystic ovarian syndrome: an observational study. Sci Rep. 2019;9:10182.

240. Kilic S, Yilmaz N, Zulfikaroglu E, et al. Inflammatory-metabolic parameters in obese and nonobese normoandrogenemic polycystic ovary syndrome during metformin and oral contraceptive treatment. Gynecol Endocrinol. 2011;27:622-9.

241. Kumar Y, Kotwal N, Singh Y, et al. A randomized, controlled trial comparing the metformin, oral contraceptive pills and their combination in patients with polycystic ovarian syndrome. I Family Med Prim Care. 2018:7:551-6.

242. Bilgir $\mathrm{O}$, Kebapcilar $\mathrm{L}$, Taner $\mathrm{C}$, et al. The effect of ethinylestradio (EE)/cyproterone acetate (CA) and EE/CA plus metformin treatment on adhesion molecules in cases with polycystic ovary syndrome (PCOS). Intern Med. 2009:48:1193-9.

243. Banaszewska B, Pawelczyk L, Spaczynski RZ, Duleba AJ. Effects of simvastatin and metformin on polycystic ovary syndrome after six months of treatment. J Clin Endocrinol Metab. 2011;96:3493-501

244. Almalki HH, Alshibani TM, Alhifany AA, Almohammed OA. Comparative efficacy of statins, metformin, spironolactone and combined oral contraceptives in reducing testosterone levels in women with polycystic ovary syndrome: a network meta-analysis of randomized clinical trials. BMC Women's Health. 2020;20:68

245. Rashid A, Ganie MA, Wani IA et al. Differential impact of insulin sensitizers vs. anti-androgen on serum leptin levels in vitamin D replete PCOS women: a six month open labeled randomized study. Horm Metab Res. 2020;52:89-94.

246. Facchinetti F, Appetecchia M, Aragona C, et al. Experts' opinion on inositols in treating polycystic ovary syndrome and non-insulin dependent diabetes mellitus: a further help for human reproduction and beyond. Expert Opin Drug Metab Toxicol. 2020;16:255-74.

247. Unfer V, Facchinetti F, Orrù B, et al. Myo-inositol effects in women with PCOS: a meta-analysis of randomized controlled trials. Endocr Connect. 2017:6:647-58.

248. Nordio M, Basciani S, Camajani E. The 40: myo-inositol/D-chiro-inositol plasma ratio is able to restore ovulation in PCOS patients: comparison with other ratios. Eur Rev Med Pharmacol Sci. 2019:23:5512-21.

249. Agrawal A Mahey R Kachhawa $G$ et al Comparison of metformin plus myoinositol vs metformin alone in PCOS 
development of symptomatic peripheral arterial disease in men. Circulation. 2002;106:820-5.

256. Bastard JP, Maachi M, Lagathu C, et al. Recent advances in the relationship between obesity, inflammation, and insulin resistance Eur Cytokine Netw. 2006:17:4-12.

257. Steinberg HO, Chaker H, Leaming R, et al. Obesity/insulin resistance is associated with endothelial dysfunction. Implications for the syndrome of insulin resistance. I Clin Invest. 1996;97:2601-10

258. Rahbar S, Natarajan R, Yerneni K, et al. Evidence that pioglitazone, metformin and pentoxifylline are inhibitors of glycation. Clin Chim Acta. 2000;301:65-77.
259. Beisswenger P, Ruggiero-Lopez D. Metformin inhibition of glycation processes. Diabetes Metab. 2003;29:6S95-103. 260. Beisswenger PJ, Howell SK, Touchette AD, et al. Metformin reduces systemic methylglyoxal levels in type 2 diabetes. Diabetes. 1999:48:198-202.

261. Ruggiero-Lopez D, Lecomte M, Moinet G, et al. Reaction of metformin with dicarbonyl compounds. Possible implication in the inhibition of advanced glycation end product formation. Biochem Pharmacol. 1999:58:1765-73.

262. Kiho T, Kato M, Usui S, Hirano K. Effect of buformin and metformin on formation of advanced glycation end products by methylglyoxal. Clin Chim Acta. 2005;358:139-45.
263. Tanaka Y, Uchino H, Shimizu T, et al. Effect of metformin on advanced glycation endproduct formation and peripheral nerve function in streptozotocin-induced diabetic rats. Eur J Pharmacol. 1999;376:17-22.

264. Sano $\mathrm{H}$, Higashi T, Matsumoto $\mathrm{K}$, et al. Insulin enhances macrophage scavenger receptor-mediated endocytic uptake of advanced glycation end products. I Biol Chem. $1998 ; 273: 8630-7$

265. Effect of intensive blood-glucose control with metformin on complications in overweight patients with type 2 diabetes (UKPDS 34). UK Prospective Diabetes Study (UKPDS) Group. Lancet. 1998;352:854-65. 